Review Articles

\title{
Review of Charge Pump Topologies for Micro Energy Harvesting Systems
}

\author{
${ }^{1,3}$ Michelle Lim Sern Mi, ${ }^{1}$ Md. Shabiul Islam, ${ }^{1}$ Jahariah Sampe and ${ }^{2}$ Sawal Hamid Md. Ali \\ ${ }^{1}$ Institute of Microengineering and Nanoelectronics (IMEN), UKM, 43600 Bangi, Selangor, Malaysia \\ ${ }^{2}$ Department of Electrical, Electronics and System Engineering, UKM, 43600 Bangi, Selangor, Malaysia \\ ${ }^{3}$ Department of Physical Sciences, TARUC, Setapak, 53300 Kuala Lumpur, Malaysia
}

Article history

Received: 29-04-2016

Revised: 19-5-2016

Accepted: 25-05-2016

Corresponding Author:

Michelle Lim Sern Mi

Institute of Microengineering and Nanoelectronics (IMEN), UKM, 43600 Bangi, Selangor, Malaysia

Email:mlsm_2002@yahoo.com

\begin{abstract}
This paper reviews CMOS based charge pump topologies used within autonomous embedded micro-systems. These charge pump structures have evolved from its simplistic diode-tied, single-branches with major threshold drops to exponential type, dual-branches with sophisticated gate and substrate control for lower voltage operation. Published charge pumps are grouped based on architecture, operation principles and pump optimization techniques with their pros and cons compared and results contrasted. The various charge pump topologies and schemes used are considered based on pumping efficiency, power efficiency, charge transferability, circuit complexity, pumping capacitors, form factor and minimum supply voltages with an optimum load. This article concludes with an overview of suitable techniques and recommendations that will aid a designer in selecting the most suitable charge pump topology especially for low ambient micro energy harvesting applications.
\end{abstract}

Keywords: Charge Pump (CP), Low Voltage (LV), Energy Harvesting

\section{Introduction}

Next generation self-powered micro devices such as medical implants dictate the need for small, safe and renewable alternatives for battery replacement. Therefore, energy can be auton omously harvested from a patient without the need of future replacement such as the cochlear implant reported in (Bandyopadhyay, 2013). When scavenging these ambient energies, there is an inevitable discontinuity, typically mitigated by use of hybrid harvesters (Shi et al., 2011; Bandyopadhyay and Chandrakasan, 2012; Lim et al., 2013; Tan, 2013; Lim et al., 2014; Yeo et al., 2016). There is also a need to resolve the cold start issue for an inherently small (low voltage) harvester input. While off-the-shelf harvesters such as Photovoltaic (PV) cells (SANYO, 2008) and Piezoelectric (PZT) harvesters (MIDE, 2013) have voltages above the CMOS voltage threshold, $V_{T H}$, Thermoelectric Generator (TEG) harvesters (CUI, 2012) generally fall in the $\mathrm{mV}$ range as low as $26 \mathrm{mV}$ (Lim et al., 2014) at $\Delta T=1 \mathrm{~K}$ when CUI Peltier device is modelled upon. Therefore, efforts to kick-start CMOS based power management circuits for low voltage harvesters ranges from providing an external bias (Carlson et al., 2010; Kim and Kim, 2013; Ahmed and Mukhopadhyay, 2014), mechanical MEMs switch
(Ramadass and Chandrakasan, 2010), charge pump based (Chen et al., 2011; Shih and Otis, 2011; Chen et al., 2012a; Liu et al., 2012; Bender et al., 2014; Peng et al., 2014), transformer based (Im et al., 2012; Teh and Mok, 2014; Zhang et al., 2014), oscillator based (Sun and Wu, 2010; Ahmed and Mukhopadhyay, 2014; Bender et al., 2014), one time wireless charging scheme (Bandyopadhyay, 2013) to a fully electrical multi-stage start-up mechanism (Chen et al., 2012b; Weng et al., 2013; Bender et al., 2014). Although these start-up scheme can push input voltage boundaries down to as low as $20 \mathrm{mV}$, they are either based on large inductors (Weng et al., 2013) and transformers (Ahmed and Mukhopadhyay, 2014; Bender et al., 2014; Teh and Mok, 2014; Zhang et al., 2014) or off-chip components (Carlson et al., 2010; Ramadass and Chandrakasan, 2010; Kim and Kim, 2013) which limits how small the system can be. To overcome the aforementioned issues, only the Charge Pump (CP) topologies will be studied in this review due to its many benefits. These benefits include the possibility of full integration, lower form factor and its simplistic pumping mechanism.

Previously published review article on $\mathrm{CP}$ circuits (Palumbo and Pappalardo, 2009) had a strong focus on design strategies and basic CP topologies. There were no mention of Low Voltage (LV) strategies and schemes for 
the recent lower supply voltage trend of micro energy harvesting systems. Therefore, this paper aims to provide a chronological summary of various CP topologies from the very first CP design up to the more recent structures with gate and substrate control techniques that tends towards LV operations. These CPs are contrasted based on standard CP design metrics including charge transferability, circuit complexity, pumping capacitors, form factor, minimum voltage supply, pumping and power efficiency.

This paper is arranged according to increasing functionality and complexity of $\mathrm{CP}$ structures and their control schemes. Hence, the second section provides a comprehensive overview of various CP architectures, techniques employed, tradeoffs and feasibility of LV operations with Table 2 summarizing critical performance metrics of contemporary CP structures. The third section concludes this paper with $\mathrm{CP}$ research trends, challenges and recommendations of $\mathrm{CP}$ structures suitable for specific design criteria especially in micro energy harvesting applications.

\section{Past Charge Pump Topologies: Overview}

Charge pumps are voltage multipliers which ideally operate in two non-overlapping clock phases. A charge pump usually requires an inverted switching signal to control both clock phases. Therefore, an oscillator is usually used to provide two out-of-phase signals in CP start-up circuits. Here, we will be focusing on the comparative study of over twenty different CP topologies and its feasibility of providing LV start-up for applications suffering from low ambient input signals below the CMOS threshold. Each of the following CPs generally addresses several improvements from their predecessor as given in the following sub-sections.

\section{Classical Charge Pumps}

The classical Cockcroft-Walton CP was originally meant for high voltage application. It has an output voltage, $V_{\text {OUT }}$ for $N$ number of stages given as $V_{\text {OUT }}=$ $2 N V_{I N}-V_{D R O P}$ where $V_{D R O P}$ is the output voltage drop and $V_{I N}$ the peak input voltage (Pan and Samaddar, 2010). Although Cockcroft-Walton CPs are still in use for particle acceleration and X-ray tubes, the architecture is not suited for LV application due to several reasons. Firstly, it has inefficient voltage lifting by serial pumping capacitor, $C_{P U M P}$ coupling; secondly, it also has significant impedance increment/stage and finally its incompatibility to monolithic integration due to large $C_{P U M P}$ requirements. Efficient boosting and drive capabilities only occur when $C_{P U M P}$ is larger than parasitic capacitance, $C_{P A R}$. This leads to the need for off-chip components due to $\mathrm{pF}$ limitations of on-chip capacitors.

Dickson (1976) CP, however is similar to CockcroftWalton except that its diode chain is coupled to $C_{P U M P}$ in shunt rather than in series. Dickson successfully demonstrated monolithic integration of a CP for the first time in 1976. Several advantages of this CP were the more efficient voltage boosting and current drivability irrespective of pump stages (Dickson, 1976) even with fairly high $C_{P A R}$ values. Later, reduction in voltage drop across diodes was possible with MOS diodes implementation (Palumbo and Pappalardo, 2010) as illustrated in Fig. 1. Its equivalent $N$-stage circuit shown in (Dickson, 1976) has a $V_{\text {OUT }}$ expression given by (Pan and Samaddar, 2010) in Equation 1 with pump clock frequency given as $f_{C L K}$ and load current given as $I_{O U T}$ :

$V_{O U T}=(N+1)\left(V_{D D}-V_{T H}\right)-N \frac{I_{O U T}}{f_{C L K} C_{P U M P}}$

Dickson's CPs are applied in non-volatile memories albeit deficiencies in LV applications below 2V (Pan and Samaddar, 2010). These drawbacks are due to voltage threshold, $V_{T H}$ drops when MOS's body terminals are reverse-biased resulting in reduced charge transfer to later stages. This body effect increases with multiplication stages and thereby reduces gain. Secondly, LV operation reduces CP's effectiveness in turning on MOS diodes due to threshold limits and conventional body biasing. Thirdly, reduction in MOS current, $I_{D}$ due to an increased in $R_{E Q}$ causes conduction losses (Peng et al., 2014), which degrades pumping efficiency and charge transferability, in which NMOS's drain current is given by $I_{D}($ sat $)=\mu_{n} \cdot C_{O X} \cdot W / L\left[2\left(V_{G S^{-}}\right.\right.$ $\left.V_{T H}\right)^{2}$ while its equivalent on resistance is given by $R_{E Q}=$ $L / \mu C_{O X}\left(V_{G S}-V_{T H}\right) W$ (Kang et al., 2014) where a wider MOS reduces $R_{E Q}$ but increases $V_{T H}$ instead.

\section{Series-Parallel Charge Pump}

The Series-Parallel CP (Fig. 2a) employs the concept of series charge (P1, P2, P4, P5 "ON") and parallel discharge (P3 and P6 "ON") when gate voltages from anti-phase clock toggles the MOS switches "ON/OFF". This CP has an $N^{\mathrm{TH}}$ stage output given by (Pan and Samaddar, 2010) as $V_{\text {OUT }}=(N+1) \cdot\left[C_{P U M P} /\left(C_{P U M P}+C_{\text {OUT }}\right)\right] V_{I N}$. It was implemented as a non-linear $\mathrm{CP}$ and employed as auxiliary step-up switch capacitor for voltage multiplications (Luo, 2009; Luo and Ye, 2009; Hart, 2011; Kang et al., 2014) but in (Luo and Ye, 2010), the Series-Parallel CPs were considered unpopular due to their discrete implementation (Lee et al., 2008). Recently, some literatures ventured into this structure (Geng and Ma, 2013; Perez-Nicoli et al., 2015; Vaisband et al., 2015), where efficient control of gate voltages (Perez-Nicoli et al., $2015)$ reduces $V_{T H}$ drops present in MOS diodes. The major drawback of this $\mathrm{CP}$ includes the $C_{P A R}$ associated with the three extra switches/stage which affects performance and the $V_{\text {OUT }}$ which strongly decreases with stage number (Luo and Ye, 2010). 


\section{Bootstrap Charge Pump}

Bootstrap CP eliminates $V_{T H}$ drops in MOS by increasing NMOS's $V_{G S}$ to $>V_{D D}+V_{T H}$ via a bootstrap capacitor, $C_{b t}$. This facilitates higher charge transfer for subsequent stages. This concept of augmenting internal node voltages $>V_{D D}$ has been demonstrated in Flash memories (Umezawa et al., 1992; Atsumi et al., 1994). The Bootstrap CP (Fig. 2b) has an additional MOS device and $C_{b t}$ per stage compared to the Dickson CP. This $V_{T H}$ cancelation scheme requires four clock phases annotated as F1, FB1, F2, FB2 in Fig. 2b with corresponding clock control signals shown in Fig. 3. The resultant $V_{\text {OUT }}$ of an $N$-stage Bootstrap CP is given by:

$$
V_{\text {OUT }}=V_{I N}+N\left[\left(\frac{C_{P U M P}}{C_{P U M P}+C_{P A R}}\right) V_{c l k}-\frac{I_{O U T}}{\left(C_{P U M P}+C_{P A R}\right) f_{c l k}}\right]
$$

where, $V_{I N}$ and $V_{C L K}$ are the input and pump clock voltages respectively. From Equation 2, several advantages of bootstrapping can be surmised, firstly, the $V_{T H}$ term is eliminated thereby reducing $V_{D R O P}$ as much as $N V_{T H}$, achieves better gain and enhance conversion efficiency, seemingly having better output efficiency compared to latch-based CPs (Allasasmeh and Gregori, 2011), a higher clock frequency can also be achieved with this four phase $\mathrm{CP}$ due to a smaller $R C$ delay as shown by the Bootstrap CP equivalent resistance of $R s=$ $N /\left(C_{P U M P}+C_{P A R}\right) f_{C L K}$. Hence, lower $R C$ delay enhances charge transfers compared to two-phase CPs. However, the Bootstrap topology suffers extra routing/area penalty and larger $C_{P A R}$ due to $C_{b \mathrm{t}}$. Also, complex clocking control strategies and gate-biasing (Yeo et al., 2015) circuitries are necessary due to its four-phase clock and $>V_{D D}+V_{T H}$ clock amplitude requirement.

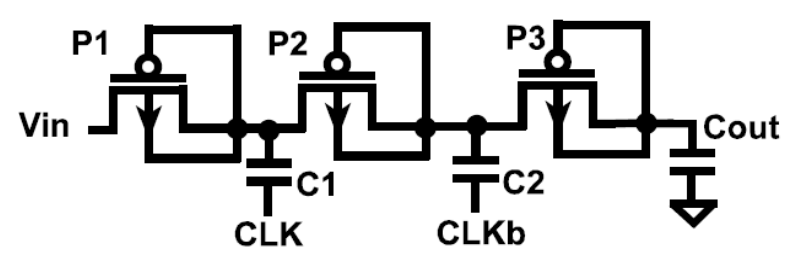

Fig. 1. Two stage Dickson charge pump

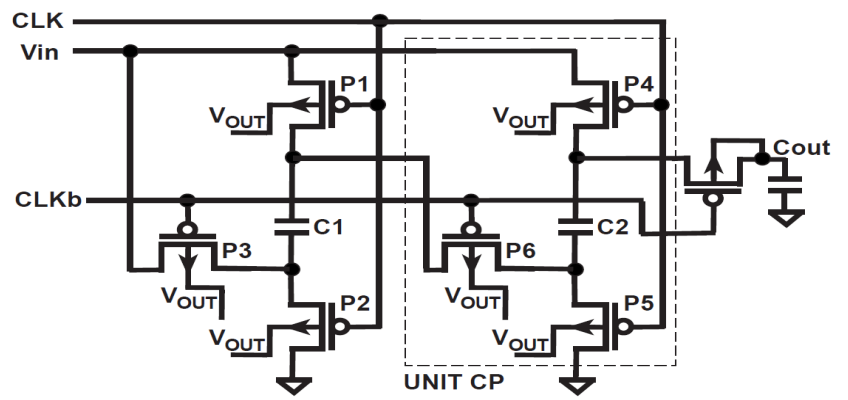

(a)

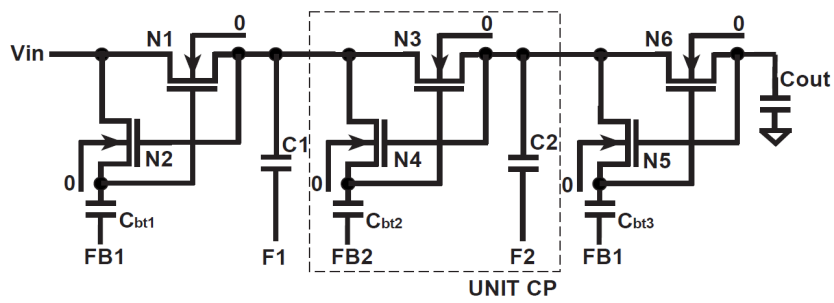

(b)

Fig. 2. Single branch charge pumps (a) series-parallel (Perez-Nicoli et al., 2014) (b) bootstrap (Pan and Samaddar, 2010)

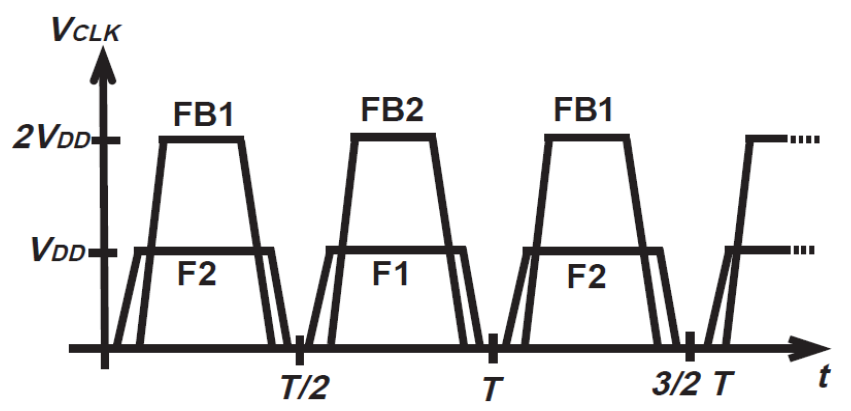

Fig. 3. Bootstrap charge pump clock control signals (Luo and Ye, 2010) 


\section{Charge Transfer Switches Charge Pump}

Static Charge Transfer Switches (CTS) charge pumps were firstly introduced by Wu and Chang (1998). The Static CTS uses dynamic feedback to improve charge transfers, gain and performance by steering charge flow from later stages of higher potentials to current stages for dynamic $V_{T H}$ cancelation This suits LV operation. Wu and Chang (1998) Static CTS have the top half structure identical to a Dickson $\mathrm{CP}$ and the extra bottom structure for $V_{T H}$ cancelation (Fig. 4a). This Static CTS suffers from reverse charge sharing which reduces pumping gain due to partially off switches. This phenomenon can be eliminated by the Dynamic CTS topology also proposed in (Wu and Chang, 1998) with two extra MOS diodes per stage (Fig. 4b). The extra PMOS and NMOS controls gate voltages and better shut down Static CTS switches. However, the final diode-connected stage still suffers from $V_{T H}$ losses due to body effect (Pan and Samaddar, 2010). The Dynamic CTS has a $V_{\text {OUT }}$ expressed as:

$$
V_{\text {OUT }}=V_{I N}+N\left[\begin{array}{l}
\left(\frac{C_{P U M P}}{C_{P U M P}+C_{P A R}}\right) \\
V_{c l k}-\frac{I_{O U T}}{\left(C_{P U M P}+C_{P A R}\right) f_{c l k}}
\end{array}\right]-V_{T H}
$$

where Equation 3 eliminates the $(N-1) V_{T H}$ term in Equation 1. However, the $C_{P A R}$ is much greater in this Dynamic CTS compared to Bootstrap CP which adds only an extra MOS and $C_{b t}$ for $V_{T H}$ cancelation. Hence, considering the area drawback, Dynamic CTS might not have an edge over Bootstrap CPs. Peng et al. (2014) describe a few losses in Dynamic CTS contributed by redistribution, conduction, reverse charge sharing losses on top of the final stage $V_{T H}$ drop. Later, Su et al. (2005) reported a Linear CP design which improved on the Dynamic CTS structure by introducing methodical gate controls to further increase pumping efficiency. As shown in Fig. 4c, NMOS were replaced by PMOS to reduce charge sharing due to the latter's lower charge mobility and its less impact on the absolute $V_{T H}$.

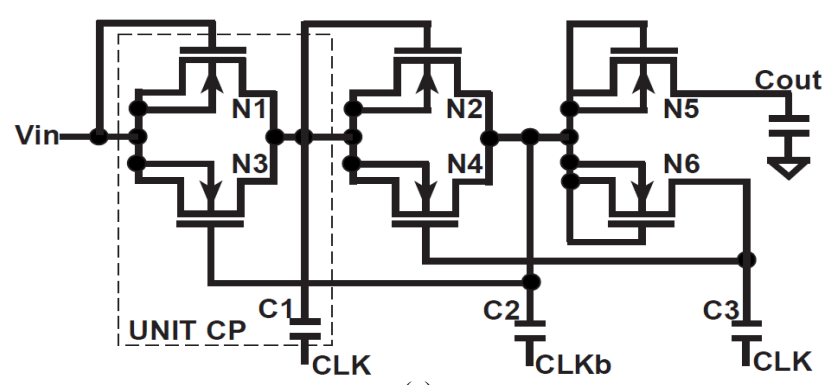

(a)

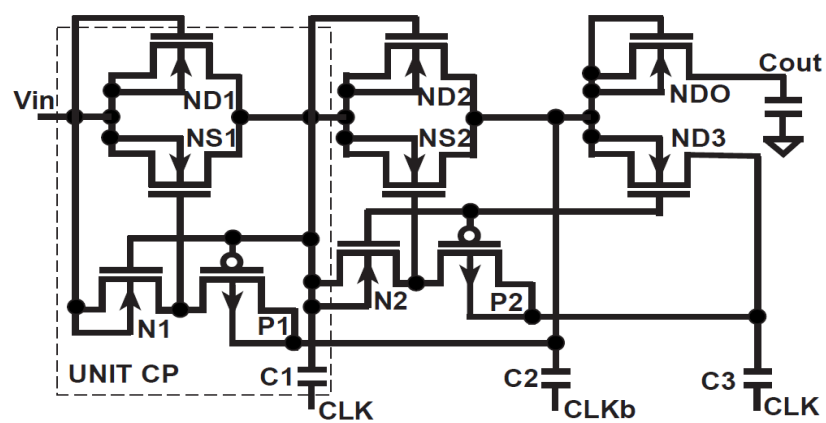

(b)

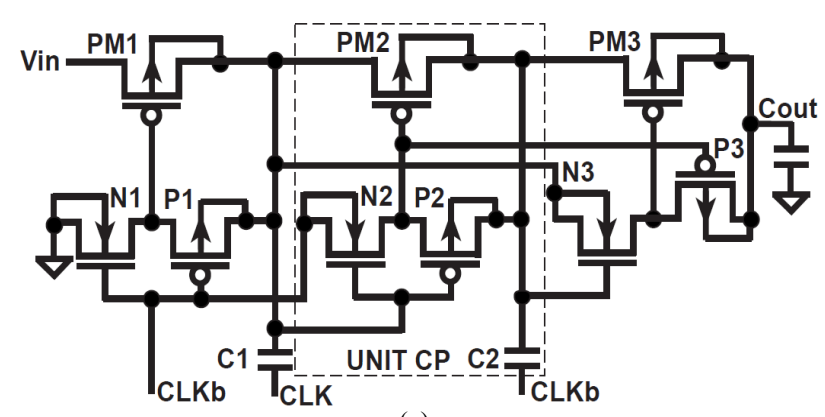

(c)

Fig. 4. Various CTS charge pumps (a) Static CTS (Wu and Chang, 1998) (b) Dynamic CTS (Wu and Chang, 1998) (c) Linear CTS (Su et al., 2005) 


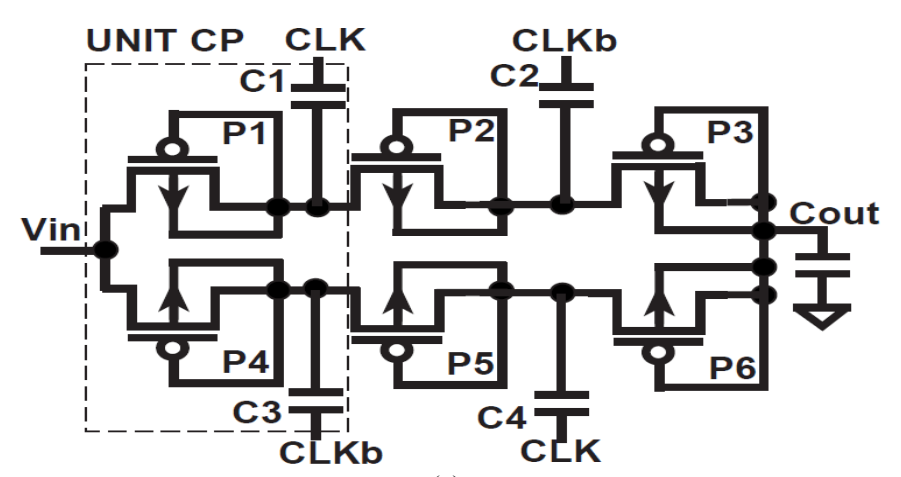

(a)

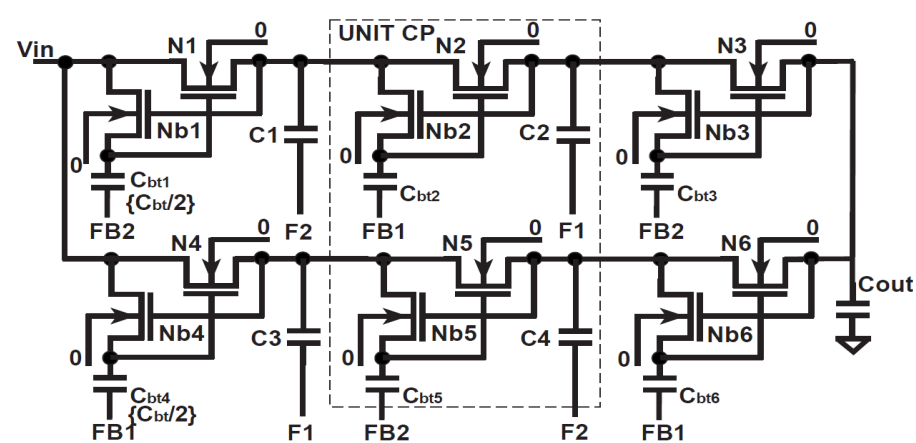

(b)

Fig. 5. Basic dual-branch charge pumps (Palumbo and Pappalardo, 2010) (a) two branch Dickson (b) two branch bootstrap

Therefore, widening PMOS reduces conduction loss (Maksimovic and Dhar, 1999) by lowering $R_{E Q}$. There is also an efficient turn-on of last stage by disregarding the use of MOS diodes as in (Wu and Chang, 1998). However, if $V_{D D}<V_{T H}$, the Linear CP yet again cannot turn on/off the switches effectively.

\section{Dual-Branch Charge Pump}

The generic Dual-Branch CP is shown in Fig. 5a while the bootstrap version for $V_{T H}$ cancelation is shown in Fig. 5b. These dual-branch structures were introduced to lower ripples in the CTS design (Kleveland, 2002; New et al., 2012) and later evolved into latch-based designs (Nakagome et al., 1991; Gariboldi and Pulvirenti, 1994; 1996; Favrat et al., 1998; Pelliconi et al., 2003; Ker et al., 2006; Che et al., 2009; Chen et al., 2010; Ulaganathan et al., 2012; Peng et al., 2014; Kim et al., 2015) which are currently gaining popularity. These structures have $V_{\text {OUT }}$ similar to Equation 1 but with reduced charge transfer intervals of $T / 2$ (Palumbo and Pappalardo, 2010), circuit minimization with smaller $C_{P U M P}$ values and half the ripple, $V_{R}$ compared to single branch CPs where $V_{R}$ is expressed as $V_{R}=I_{O U T} T /\left[2\left(C_{O U T}+C_{P U M P}\right)\right]$ (Pan and Samaddar, 2010) assuming $C_{\text {OUT }}>>C_{P U M P}$. The aforementioned advantages translate to $V_{D R O P}$ reduction, higher switching frequencies and the possibility of LV start-up. Although, ripples associated to noise that affects loads such as memory can be reduced by increasing $C_{L O A D}$ and $f_{C L K}$, these strategies adversely lengthen ramp-up time and reduces pump efficiency respectively. Since Dual-Branch CPs are still not suited for LV operation and cold-start circuits, they were later evolved into cross-coupled structures with body biasing (Peng et al., 2014; Kim et al., 2015) and dynamic gate controls (Su et al., 2005) to complement LV operations.

\section{Cross-Coupled Charge Pump}

The Cross-Coupled CPs were originally proposed in (Gariboldi and Pulvirenti, 1994; 1996) and later implemented as a four stage cascaded version in Ker et al. (2006) CP design. The Cross-Coupled topologies are realized with cross-coupled switches driven by antiphase clocks for boosted voltages. They are essentially latch-configured inverters with $V_{O U T}$ similar to the DualBranch CPs. These dual compensated structures introduce many benefits akin to the dual-branch structures. Not only does it improve pumping efficiency and reduces ripples as reported in (New et al., 2012), these CPs enhances charge transferability and requires smaller devices, i.e., half the original $C_{P U M P}$ size, which in turn reduces effect of device sizes on $V_{T H}$ (Peng et al., 2014). Moreover, redistribution loss is also reduced as the branches complements charge transfer to the output node, ensuring load voltage stability. Since this CrossCoupled CP normally fails to work below $V_{T H}$, several schemes were introduced to mitigate this. The following 
elaborates some evolved structures since the classical latched CP design in (Gariboldi and Pulvirenti, 1994) beginning with Ker et al. (2006) structure to the most recent of developments. Ker et al. (2006) CP (Fig. 6a) has intertwining anti-phase clock signals on two branches with source-connected NMOS bulks to eliminate body effects while Che et al. (2009) design uses only PMOS for this purpose. These structures with two latch-based branches eliminate $V_{T H}$ drops, inherent to classic CPs (Dickson, 1976; Wu and Chang, 1998) for an almost full charge transfer between stages. With reduced reverse charge sharing compared to the Dynamic CTS, they are still not suited for LV applications especially when $V_{I N}$ is a few hundred $\mathrm{mV}$ below $V_{T H}$, inapt at effectively turning on MOS switches.

Recently, Peng et al. (2014) (Fig. 6b) improved on Ker et al. (2006) design where body biasing and backward control was reported in (Peng et al., 2014). This scheme enables complete turn on/off of the MOS transistors. Therefore, switching losses and reverse charge sharing were reduced. Body-biasing and the sub-threshold regime were included to enable LV operation. Although Peng et al. (2014) two branch CP
(2014) solved most of Ker et al. (2006) design with a good efficiency of $89 \%$, swift $0.1 \mathrm{~ms}$ pumping speed, high capacitive drivability and charge transferability, its reported minimum start-up voltage is still high at $320 \mathrm{mV}$ with a rather complex scheme requiring interleaved inverters and extra stages at the end. Moreover, such body-biasing will cause leakages if not well controlled. An alternative was Nakagome et al. (1991) circuit (Fig. 7a) which utilizes cross-coupled NMOS cells to obtain lifted voltage levels where differential outputs of the cells are coupled to form a single output using dual series-connected PMOS load switches (Nakagome et al., 1991). This would avoid large $V_{D R O P}$. However, Nakagome et al. (1991) CrossLoad CP suffers from low conduction due to gate drive capabilities of PMOS load switches and no gains from series switches when $V_{I N}<V_{T H}$ or when $V_{O U T}$ is minute due to heavy loads (Kim et al., 2015). Recently, literatures in (Favrat et al., 1998; Chen et al., 2010; Ulaganathan et al., 2012; Kim et al., 2015) provide improved versions of this Cross-Load CP (Nakagome et al., 1991) to enhance these constraints associated to LV start-up operations.

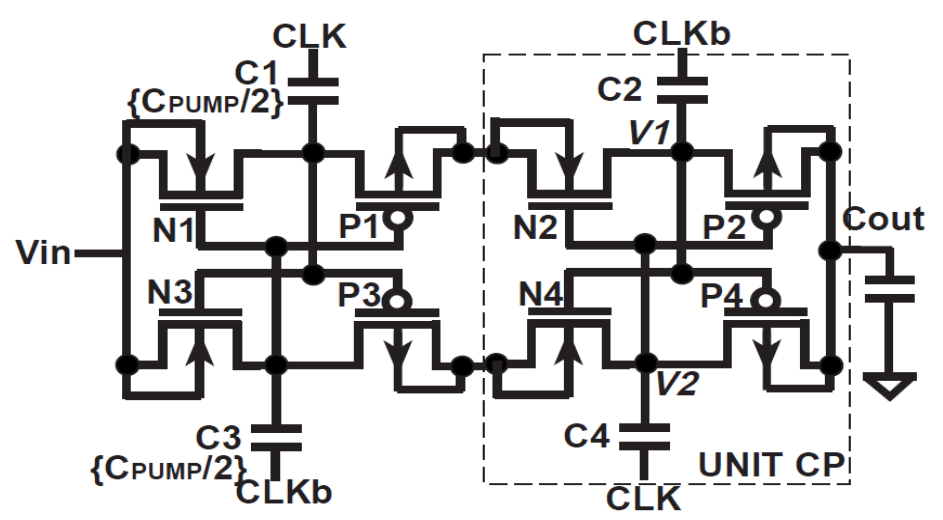

(a)

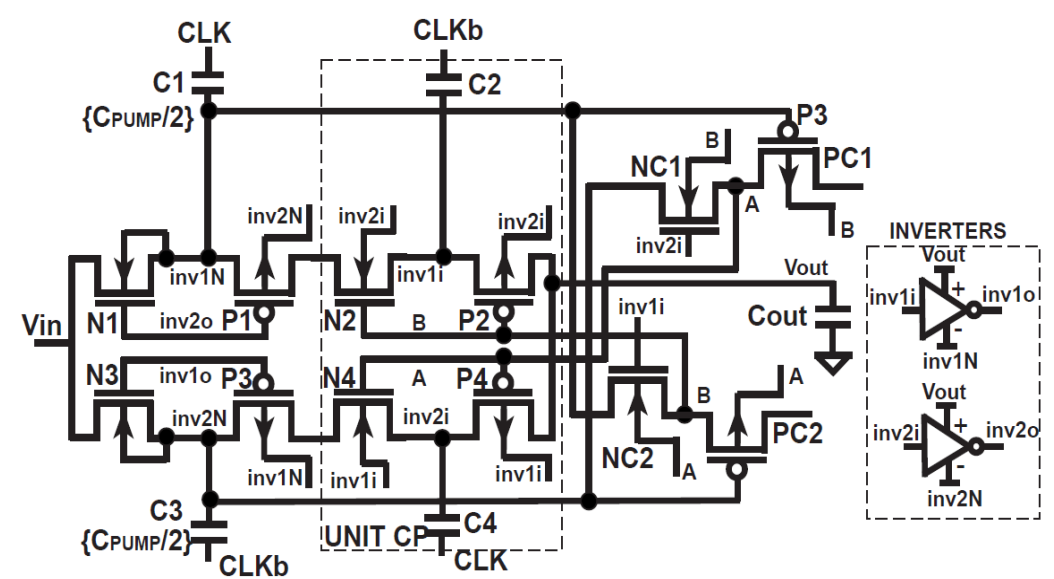

(b)

Fig. 6. Cross-coupled charge pumps (a) classic latched based (Ker et al., 2006) (b) Peng et al. (2014) variation 


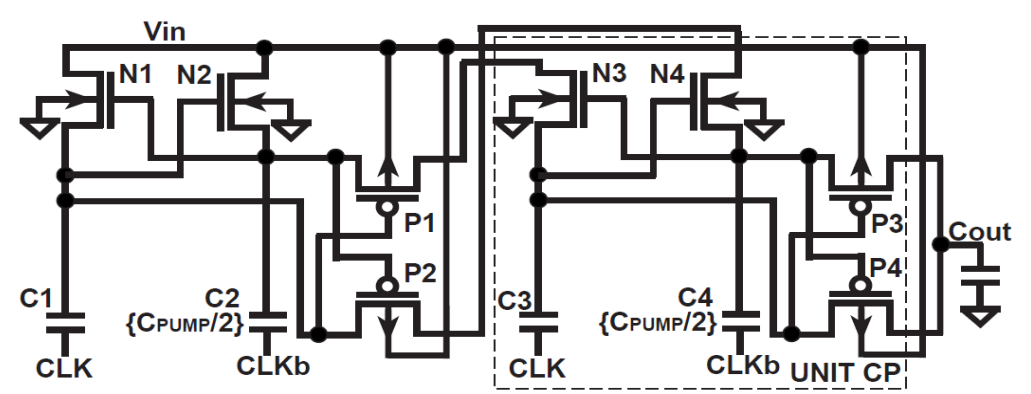

(a)

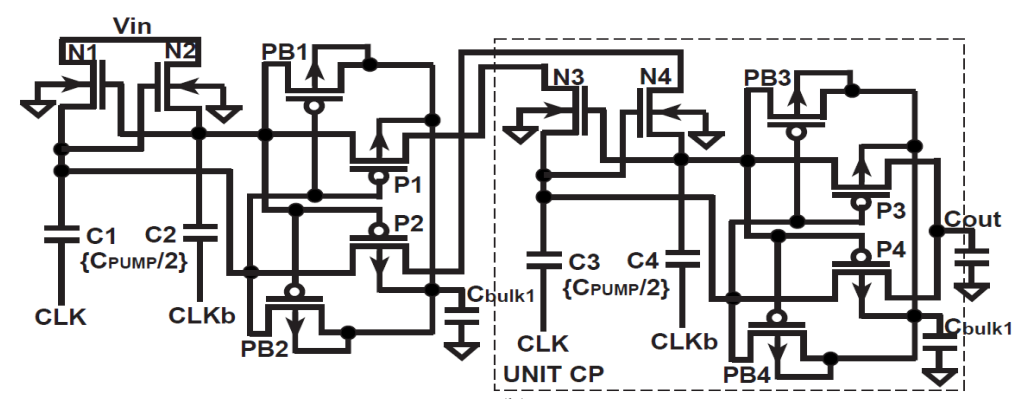

(b)

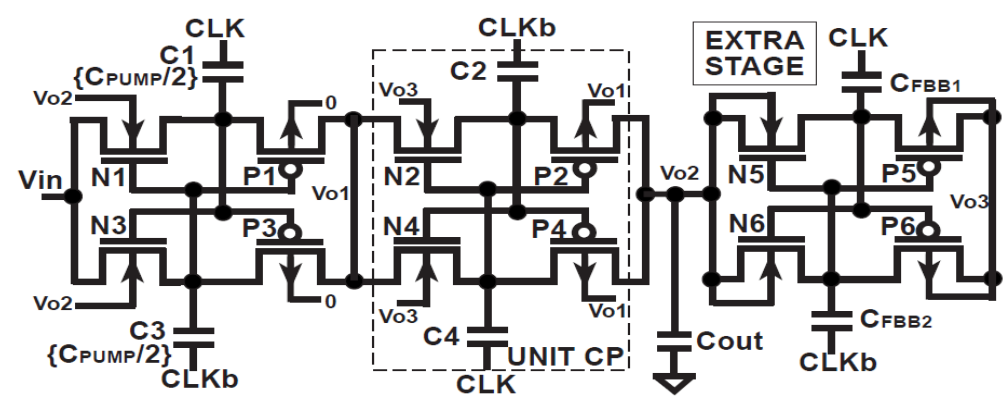

(c)
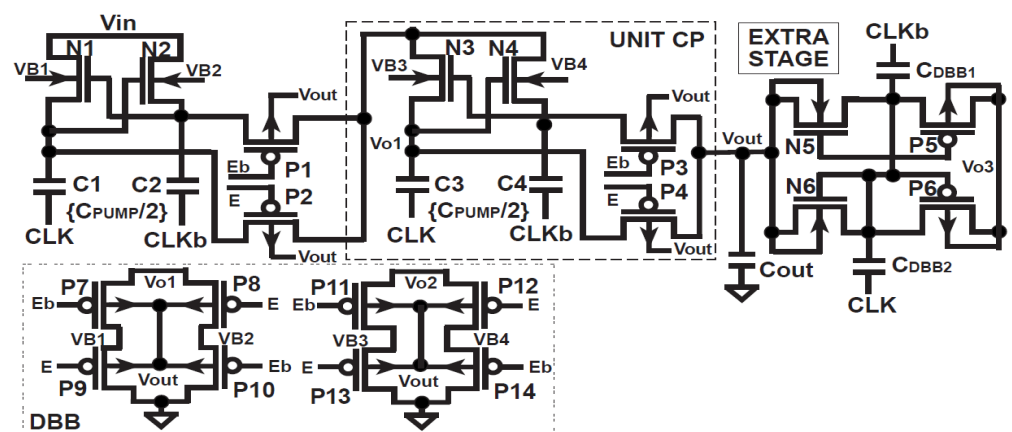

(d)

Fig. 7. Cross-couple charge pumps with various body biasing topologies (a) cross-loads (Nakagome et al., 1991) (b) bulk-switching (Favrat et al., 1998) (c) forward body-biasing (Chen et al., 2010) (d) dynamic body-biasing (Kim et al., 2015)

To resolve lower conduction levels of the Cross-Load CP (Nakagome et al., 1991; Favrat et al., 1998) proposed a Bulk-Switching CP (Fig. 7b) with better switch conductance due to a level shifter gate signal control but this Bulk-Switching fails at low voltages due to backward current via series switches (Kim et al., 2015). Conventionally, both Cross-Load (Nakagome et al.,
1991) and Bulk-Switching (Favrat et al., 1998) CPs have their PMOS's/NMOS's bulk biased to the highest/lowest potential. This ensures parasitic diodes inherent to MOS devices are reverse-biased to avoid leakages in off-state NMOS as well as degradation of PMOS voltage swing at the output node. Although the Cross-Load and BulkSwitching CPs have low leakages, they suffer low on- 
current, $I_{O N}$. The low gain in Cross-Load CP is also unresolved in the Bulk-Switching CP due to weakly off switches. Hence, increasing (decreasing) NMOS's (PMOS) body bias reduces $V_{T H}$ to facilitate lower turnon voltages such as the Forward-Body-Bias (FBB) CP proposed by (Chen et al., 2010; Peng et al., 2014).

The FBB CP uses higher inter-stage voltages borrowed from future stages to reduce $V_{T H}$ of NMOS while PMOS is biased to the lowest ground potential (Fig. 7c). Thus, all MOS devices are forward biased at all times during both "ON" and "OFF" states. This leads to both high current transfer and high body leakages when MOS devices are not conducting. This increases Voltage Conversion Efficiency (VCE) but reduces Power Conversion Efficiency (PCE). To resolve this issue, the Dynamic-Body-Biasing (DBB) CP was proposed by Kim et al. (2015) recently (Fig. 7d) with consideration of dead-time limitations, conduction loss and Meindl limit (Meindl and Davis, 2000). The DBB $\mathrm{CP}$ maintains a high on current during "ON" states and at the same time reduce leakages during "OFF" states by dynamically switching MOS devices into low $V_{T H}$ (forward-biased) and high $V_{T H}$ (reverse-biased) devices on demand, widely known as the Variable Threshold CMOS technique (VTCMOS) (Kang et al., 2014). The low $V_{T H}$ enables LV operation and faster speed whereas higher $V_{T H}$ reduces sub-threshold leakages and enhances efficiency. While the DBB CP in (Kim et al., 2015) have benefits such as low processing cost, low start-up voltages at $150 \mathrm{mV}$, high efficiency of $72.5 \%$ at $V_{I N}=$ $450 \mathrm{mV}$ and reduced leakages while maintaining high on current which promotes LV applications, the structure suffers from additional DBB control circuitry, usages of $6 \times 10 \mathrm{nF}$ off-chip capacitors and still a low $34 \%$ pumping efficiency at low voltages $(180 \mathrm{mV})$. On the other hand, Bandyopadhyay et al. (2014) proposed an ultra low power CP similar to Fig. 7b with a gate driver that reduces leakages based on Favrat et al. (1998) voltage doublers model.

\section{Adiabatic Charge Pump}

Adiabatic CP uses adiabatic switching to lower power consumption. It employs energy recycling by rerouting charge transfer paths back to the source/load rather than discharging to ground potential. Literatures in (Lauterbach et al., 2000; Keung et al., 2007; Ulaganathan et al., 2012) used adiabatic switching to reduce power usage. Lauterbach et al. (2000) uses dualstep adiabatic switching, charge sharing and a simple clocking technique that two-folds power efficiency. Keung et al. (2007) uses this concept on highly parallel datapaths in DSPs by recycling charge with an Adiabatic $\mathrm{CP}$, moving slower adiabatic components away from critical paths. This successfully reduced energy consumption by $18 \%$ with a $1-2 \%$ area penalty.
Recently, switching losses linking to CTS gate control is reduced in (Ulaganathan et al., 2012) by using adiabatic switching scheme on the CTS structure (Fig. 8a). The Adiabatic CP has its $V_{\text {OUT }}$ similar to Equation 2 albeit with a lower energy dissipation where $E_{C P}=Q V_{D D}$ and $E_{A}=3 / 4 Q V_{D D}$ represents energy dissipation of conventional one-step and multi-step adiabatic charging respectively (Lauterbach et al., 2000). Adiabatic schemes focus on lowering power consumption by an almost zero energy exchange with the environment in the expense of slower charging time, additional circuitry such as transmission gates as well as the need of a pulsed voltage source (Kang et al., 2014) for stepwise charging.

\section{Mixed Structure Charge Pump}

Mixed Structure CP such as those reported in (Hsieh et al., 2009; Huang et al., 2010) employs more than one type of CP structure per stage (Fig. 8b). These literatures combines CTS and Cross-Coupled CP to address both reverse charge sharing (Huang et al., 2010) and the final stage $V_{T H}$ drop with better pumping gain compared to traditional CTS structures (Wu and Chang, 1998). The Mixed Structure CP in (Huang et al., 2010), however, improves the original mixed structure in (Hsieh et al., 2009) by using multi-phase technique to enhance pumping and power efficiency. The penalties of such hybrid structures are generally the larger form factor and more complicated control schemes. These structures produce a $V_{\text {OUT }}$ similar to the CTS as expressed in Equation 3 indicated by (Hsieh et al., 2009).

\section{Adaptive Charge Pump}

Adaptive $\mathrm{CP}$ ranges from CPs that changes its voltage conversion ratios (Zhang and Lee, 2010; Beck and Singer, 2011; Vaisband et al., 2015) or stage number (Tanzawa et al., 2002) on demand to reconfigurable CPs that modifies itself to maximize current in linear mode or switches to Fibonacci mode for LV operations such as the Adaptive CP structure proposed in (Gupta et al., 2013), sleep-active mode CP transitions in (Alioto et al., 2013) as well as topological modifications from Heap, Exponential to Fibonacci in (Allasasmeh and Gregori, 2011). Figure 8c shows an Adaptive CP (Palumbo and Pappalardo, 2010) that enables one to three stage number modifications by dividing total capacitance, $C_{T O T}$ with a suitable number of $C_{P U M P}$ assigned by MOS switches and driven by appropriate phase inputs. These phases, F1 through F6 with its corresponding complementary signals $(F X$ and $F N$ ) are shown in Fig. 9 (Palumbo and Pappalardo, 2010). The merits of Adaptive CP is its flexibility and that it dynamically lowers power consumption when usage level or purpose changes. However, the Adaptive CPs constitute a larger area and are more complex in their configurations and switching schemes compared to their non-adaptive counter parts. 


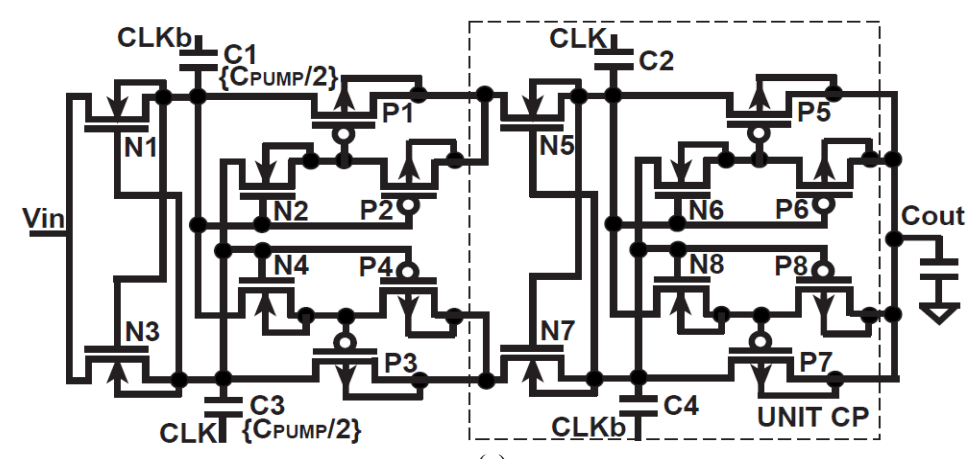

(a)

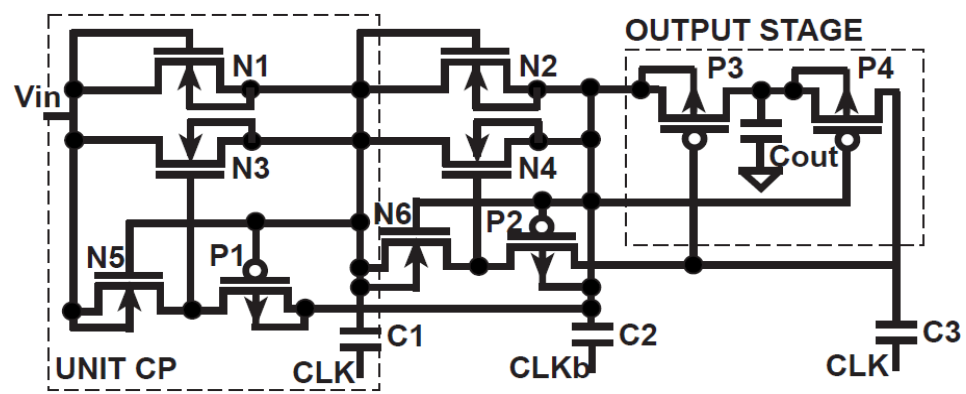

(b)

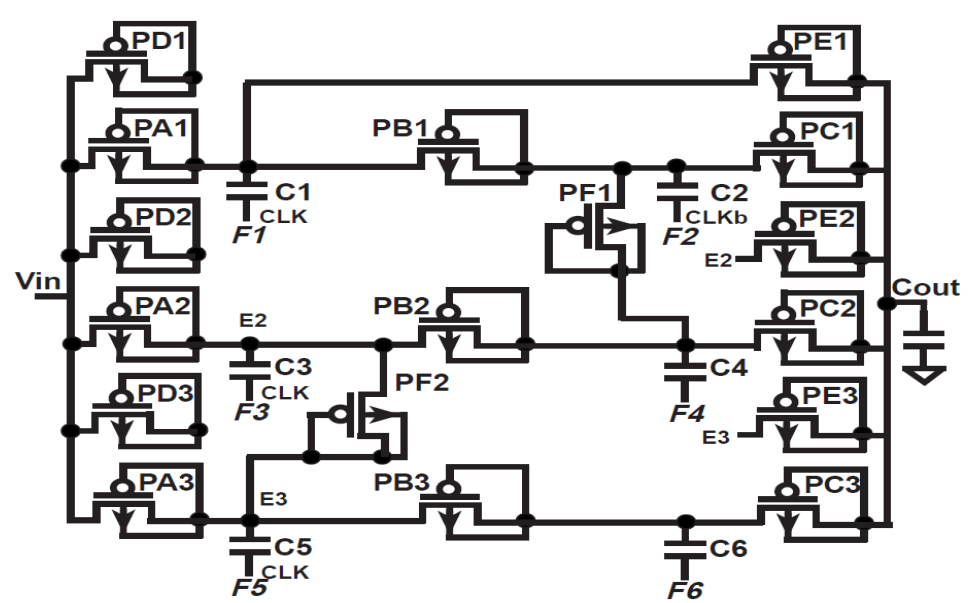

(c)

Fig. 8. Special purpose charge pumps (a) Adiabatic (Ulaganathan et al., 2012) (b) Mixed Structure (Hsieh et al., 2009) (c) Adaptive (Palumbo and Pappalardo, 2010)

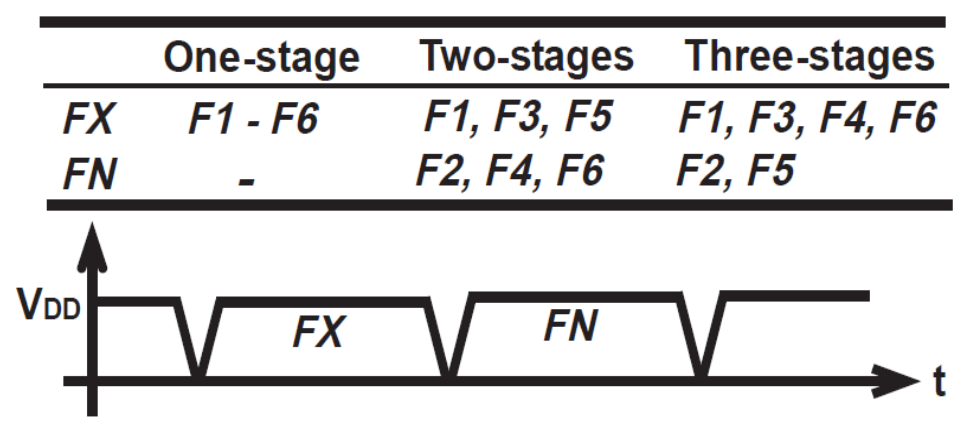

Fig. 9. Input/complimentary signals of adaptive CP (Palumbo and Pappalardo, 2010) 


\section{Single Clock Charge Pump}

Single Clock CP were introduced in (Ansari et al., 2011) and enhanced in (Mondal and Paily, 2013). While previously discussed CPs uses more than one clock, the Single Clock CP needs no extra circuitry to ensure nonoverlap of a second clock. As (Ansari et al., 2011) feeds low supply voltages to each stage (Fig. 10a), (Mondal and Paily, 2013) enhances $V_{\text {OUT }}$ by feeding only the first stage with supply voltages and subsequent stages with internally boosted voltages from later stages (Fig. 10b). Thus, the $V_{\text {OUT }}$, transferable charge, $Q_{N}$ and $I_{\text {OUT }}$ for both $N$-stage conventional and enhanced-voltage Single Clock CP is summarized in (Mondal and Paily, 2013). While Mondal and Paily (2013) enhances $V_{\text {OUT }}$ up to 9 and $18 \%$ as compared to the Dickson and Conventional Single Clock structure (Ansari et al., 2011), it suffers from poor charge sharing time compared to both structures.

\section{Miscellaneous Charge Pumps}

Miscellaneous CPs are shown in Fig. 11 and 12 representing Ladder CP (Bender, 1994; Seeman and Sanders, 2008; Bazzini et al., 2012), Fibonacci CP (Ueno et al., 1991; Makowski and Maksimovic, 1995; Seeman and Sanders, 2008; Allasasmeh and Gregori, 2011; Gupta et al., 2013), Exponential CP (Cernea et al., 2009; Allasasmeh and Gregori, 2011) and a recently patented Tree Topology CP (Lu et al., 2010; Roy et al., 2014) respectively. As stated in (Seeman and Sanders, 2008), Series Parallel CP performs better in a capacitor limited process with impedance inversely proportional to frequency while the Dickson and Ladder CP (Fig. 11a) works best in a switch limited process (Seeman and Sanders, 2008) with frequency-independent constant current flow. Hence, the CPs either uses switches or capacitors efficiently, but not simultaneously superior in both asymptotes (Seeman and Sanders, 2008). Recently, Bazzini et al. (2012) proposes an all PMOS Double Ladder CP which lowers output resistance, $R_{O U T(O P T)}=$ $\left(N^{2}(N+1)^{2}\right) / 4 f_{C L K} C_{T O T}$ compared to Pelliconi et al. (2003) design with the $i$-stage pumping capacitor, $C_{P U M P(i)}=$ $(N+1-i) /\left(N(N+1) C_{T O T}\right.$ (Bazzini et al., 2012) chosen to minimize $R_{\text {OUT }}$ (Makowski and Maksimovic, 1995). While this enhanced structure has a high VCE at $93 \%$, it still suffers a low PCE at 52\%.

A two-stage Fibonacci CP (Fig. 11b) has reasonable switch and capacitor efficiency as reported in (Seeman and Sanders, 2008). The Fibonacci structure also has good current drivability in LV ranges (Gupta et al., 2013), low ripples and a good pump-up ratio (Ueno et al., 1991) due to its non-linearity and exponential nature. Fibonacci CP's operation as explained in (Allasasmeh and Gregori, 2009) has the same gain with Dickson CP albeit having fewer capacitances. Also, it has a Fibonacci sequence as its per-stage voltage ratio giving $V_{O U T(F C P)}=$ $G V_{I N}-I_{\text {OUT }} R_{\text {OUT }}$ where $G$ is the Fibonacci CP's ideal voltage gain, $G=F_{N+1}, F_{N}$ is the $N$-th Fibonacci number and $C_{i}$ is the $i$-th $C_{P U M P}$ value. From Table $1, R_{O U T}$ has more significant stage growth in Dickson CP compared to Fibonacci CP. Hence, the Fibonacci structure has lower conduction losses given by $P_{R}=$ $I_{\text {OUT }}{ }^{2} R_{\text {OUT }}$ leading to better energy efficiency than the Dickson structure (Allasasmeh and Gregori, 2009) for $G>3$. There are however no difference in $R_{\text {OUT }}$ between them for $\mathrm{G} \leq 3$ or $\mathrm{N} \leq 2$. Unlike Dickson CPs, $C_{P U M P}$ in Fibonacci CPs are not equally sized in all stages. For optimal performance, the $N$-th stage Fibonacci CP requires the largest capacitor nearest to $V_{I N}$ and the smallest capacitor to be closest to the load.

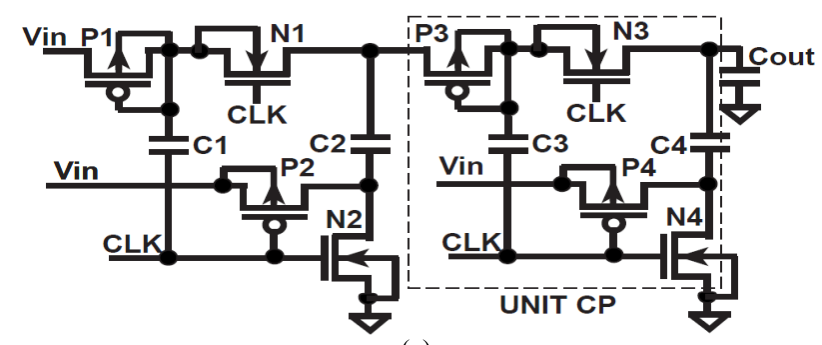

(a)

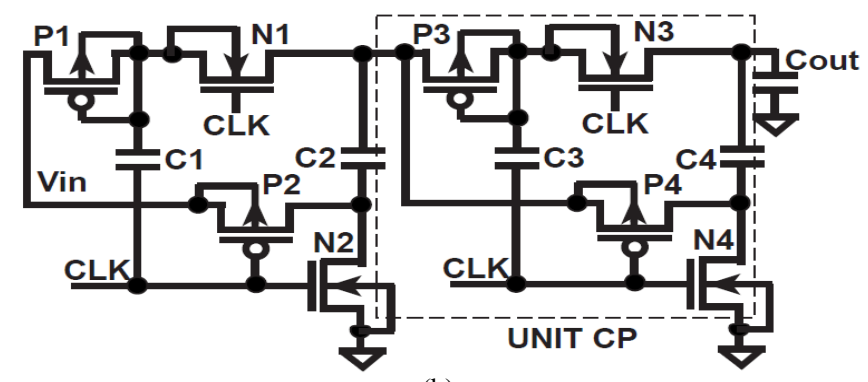

(b)

Fig. 10. Single clock charge pumps (a) conventional (Ansari et al., 2011) (b) enhanced output voltage (Mondal and Paily, 2013) 


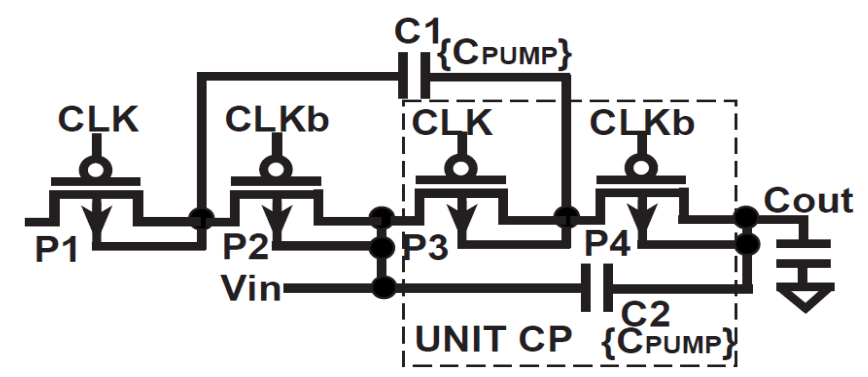

(a)

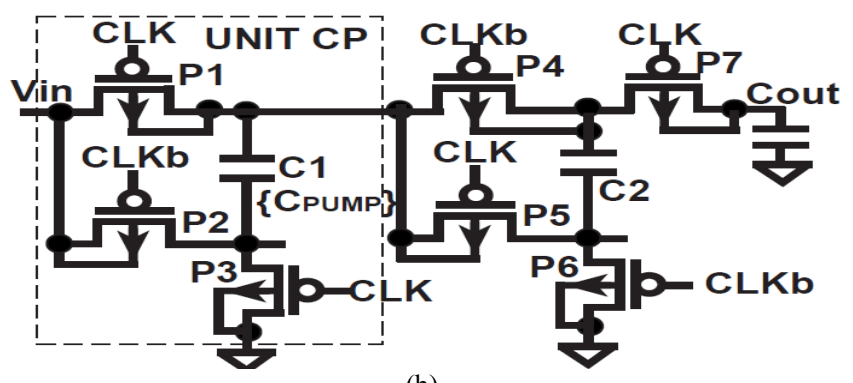

(b)

Fig. 11. Miscellaneous charge pump topologies (Seeman and Sanders, 2008) (a) Ladder charge pump (b) Fibonacci charge pump

Exponential CPs have voltage gain exponentially associated to their pumping stages (Chang and $\mathrm{Hu}, 2004$; 2006; Gobbi et al., 2007; Seeman and Sanders, 2008). Fibonacci CPs (Ueno et al., 1991; Allasasmeh and Gregori, 2011; Gupta et al., 2013) and voltage doublers (Seeman and Sanders, 2008) are categorized as exponential or non-linear CPs. Figure 12a shows an Exponential CP applied to a Flash memory (Cernea et al., 2009) with reduced area and 50\% lower internal impedances for the same pumping capabilities of past topologies. Chang and $\mathrm{Hu}$ (2006) proposed their Exponential CPs (Fig. 12b) to reduce CP stages with the same achievable gain considering per-stage $V_{T H}$ drop in MOS switches. The exponential structure in (Chang and $\mathrm{Hu}, 2004$; 2006) also suppresses $V_{T H}$ problems by having a larger clock voltage growth rate as compared to $V_{T H}$ drop rate (Chang and $\mathrm{Hu}, 2004)$. This solves the voltage saturation issue due to augmented $V_{T H}$ and lower $V_{O U T}$ in linear structures (Chang and $\mathrm{Hu}, 2006$ ). Suitable $W / L$ ratios are selected for better gain and voltage transferability by having a proportional decrease in transistor sizes from input to the load stage (Chang and $\mathrm{Hu}, 2004$ ). Later, (Shao et al., 2006) improved $V_{\text {OUT }}$ boosting by area as summarized by Gobbi et al. (2007) in Table 1 where even though Exponential CPs have the best gain at the same area, it suffers from a dramatic increase in $R_{\text {OUT. }}$. Gobbi et al. (2007) compared Chang and $\mathrm{Hu}$ (2006) Exponential CP to the Fibonacci and Dickson $\mathrm{CP}$ in terms of gain, $R_{O U T}$ and pump-up speed. Moreover, a larger voltage loss can be seen with Exponential CP's $V_{O U T}$ expression given by $V_{\text {OUT }}(E C P)=G V_{I N}-\Delta V_{\text {OUT }}=$ $2^{N} V_{I N}-I_{\text {OUT }} R_{\text {OUT }}$
Finally, the patented TTCP (Fig. 12c) resolves the charge transfer capability of linear CPs which is subjected to degradation when used with LV energy transducers by coupling more than one stage of the CP to the energy harvesting source (Lu et al., 2010; Roy et al., 2014). On the other hand, a Negative Charge Pump (NCP) can provide negative output voltages with similar configurations to a basic Dickson CP only to be replaced by a ground voltage at the input terminal (Pan and Samaddar, 2010). Table 2 summarizes the results for CMOS based CPs extracted from research papers in the past eight years. These CPs are compared based on their CMOS feature size, topology, clock frequency, minimum supply ranges, load current/load capacitor sizes, pumping capacitor sizes, VCE and PCE respectively. Generally, VCE is given as the actual output voltage over the ideal pumped-up voltage $\left(V_{O U T} / V_{I D E A L}\right)$ given by $\eta_{V}=\left(V_{O U T} /(N+1) V_{I N}\right)$ for linear CPs (Palumbo and Pappalardo, 2010) while PCE is a measure of power extraction efficiency from source to the load given by $\eta_{P}=\left(I_{O U T} V_{O U T} / I_{C O N} V_{D D}\right)$. From Table 2, it can be noted that throughout the years from 2008 to 2016, researchers have successfully pushed start-up voltage levels from $1.5 \mathrm{~V}$ (Su and Ma, 2008) all the way down to $40 \mathrm{mV}$ in Ashraf and Masuomi (2016) simplistic FBB based Dickson structure with a demerit of slow $\sim 8 \mathrm{~s}$ start-up time. These recent $\mathrm{CP}$ topologies have advanced towards body-biasing (Zhang and Lee, 2013; Peng et al., 2014; Kim et al., 2015; Ashraf and Masuomi, 2016) and gate controls (Shih and Otis, 2011; Zhang and Lee, 2013) for VCE enhancements of $\sim 86 \%(180 \mathrm{mV})$ in Kim et al. (2015) structure and $\sim 93 \%(350 \mathrm{mV})$ in Shih and Otis (2011) Bootstrap CP design. 


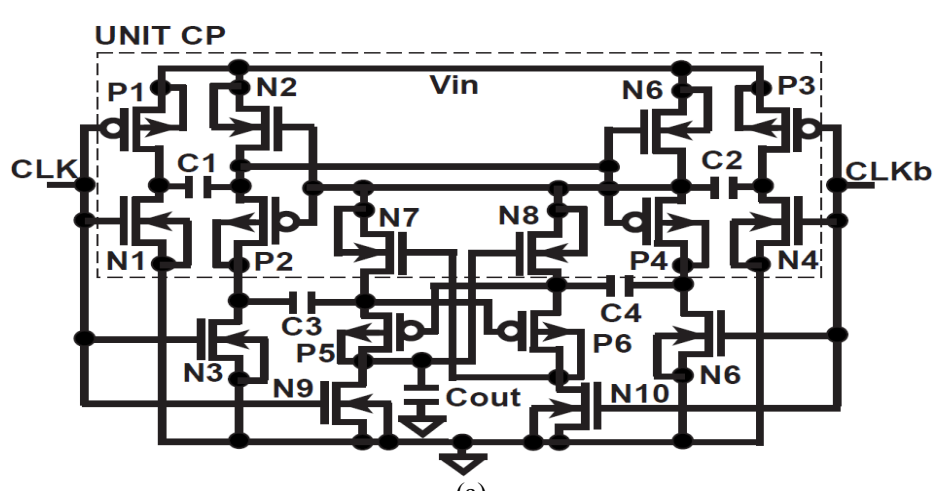

(a)

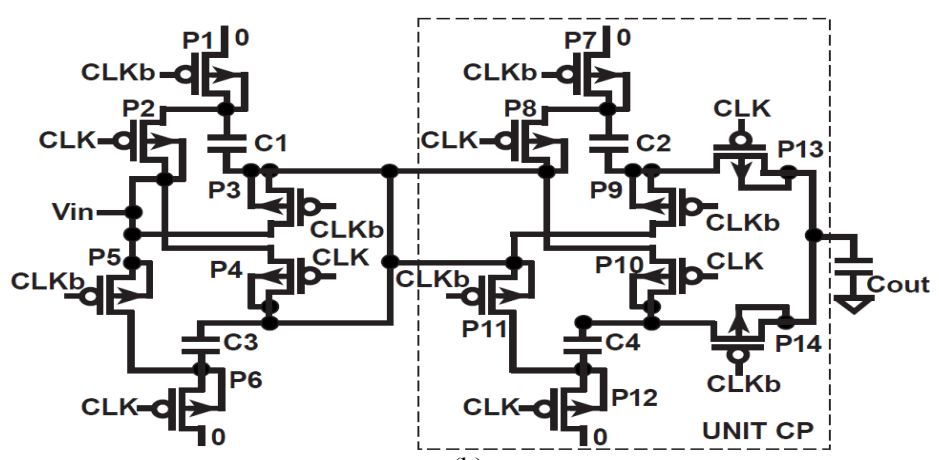

(b)

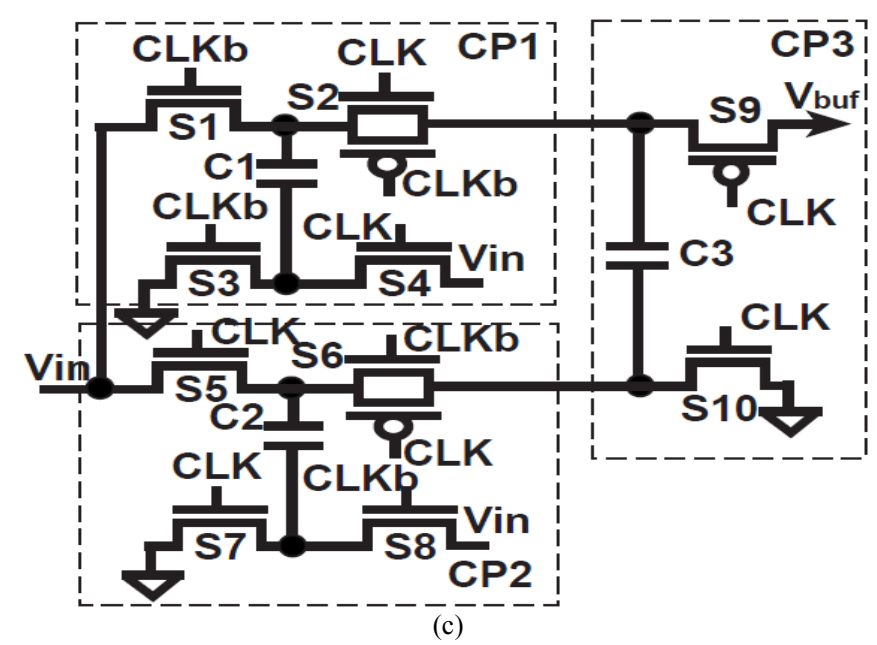

Fig. 12. Miscellaneous charge pump topologies: (a) Exponential (Cernea et al., 2009) (b) exponential-gain structure (Chang and Hu, 2006) (c) Tree-topology (Lu et al., 2010; Roy et al., 2014)

Table 1. Comparison of voltage gain, output resistance and silicon area between N-stage charge pump topologies (Gobbi et al., 2007)

\begin{tabular}{llll}
\hline & ECP & FCP & DCP \\
\hline Voltage Gain, G & $2^{N}$ & $F_{N+1}$ & $N+1$ \\
Output Resistance, R & $\left(F_{N} F_{N-1}\right) / f C$ & $N / f C$ \\
Silicon Area & $2^{N} \sum_{i=1}^{N}\left(2^{i-1}\right)^{2} / f C$ & $\mathrm{NC} / \mathrm{C}_{\square}$ & $\mathrm{NC} / \mathrm{C}_{\square}$ \\
\hline
\end{tabular}

In a nutshell, current $\mathrm{CP}$ design trends tend towards the lower power spectrum with prominence given to $V_{T H}$ cancellation schemes, $R C$ delay reduction and raising of on/off current ratio (DBB schemes) when considering $\mathrm{CP}$ design metrics trade-offs in $\mathrm{LV}$ operations. 


\begin{tabular}{|c|c|c|c|c|c|c|c|c|c|}
\hline \multirow[b]{2}{*}{ Authors (Year) } & \multicolumn{9}{|l|}{ Parameters } \\
\hline & $\begin{array}{l}\text { CP Topology } \\
\text { (No. of stages/ } \\
\text { Branches) }\end{array}$ & $\begin{array}{l}\text { Minimum } \\
\text { supply, } \\
V_{I N}\end{array}$ & $\begin{array}{l}\text { Clock } \\
\text { Frequency, } \\
f_{C L K}\end{array}$ & $\begin{array}{l}\text { Pumping } \\
\text { Capacitors, } \\
C_{P U M P}\end{array}$ & $\begin{array}{l}\text { Load/ Load } \\
\text { Capacitor, } \\
I_{O U T} / C_{L O A D}\end{array}$ & $\begin{array}{l}\mathrm{VCE} \\
(P C E)\end{array}$ & $\begin{array}{l}\text { Process } \\
\text { technology } \\
\text { (CMOS) }\end{array}$ & Advantages & Disadvantages \\
\hline $\begin{array}{l}\text { Ashraf and } \\
\text { Masoumi (2016) }\end{array}$ & $\begin{array}{l}\text { Dickson with } \\
\text { FBB } \\
(5 \times 20 \text {-stages } / 1)\end{array}$ & $40 \mathrm{mV}$ & $1 \mathrm{kHz}$ & N/A & $\begin{array}{l}C_{L O A D}=5 \mathrm{nF} \\
\text { (CP output) }\end{array}$ & $\begin{array}{l}53.88 \% @ 40 \mathrm{mV} \\
\text { (N/A) }\end{array}$ & $180-\mathrm{nm}$ & $\begin{array}{l}\text { Lowest } V_{I N} \\
\text { Simplistic FBB }\end{array}$ & $\begin{array}{l}\text { Slow pre-startup at } \sim 8 \mathrm{~s} \\
\text { Large no. of MOSFETs } \\
\text { approach }\end{array}$ \\
\hline Kim et al. (2015) & $\begin{array}{l}\text { Cross-coupled } \\
\text { with DBB } \\
(3 \text {-stages } / 2)\end{array}$ & $150 \mathrm{mV}$ & $\begin{array}{l}250 \mathrm{kHz} \\
\text { (off-chip) }\end{array}$ & $\begin{array}{l}10 \mathrm{nF} \times 6 \\
\text { (a) } V_{I N}=0.18 \mathrm{~V}\end{array}$ & $\begin{array}{l}I_{\text {OUT }}=21 \mathrm{uA} \\
V\left[V_{\text {OUT }}=0.5 \mathrm{~V}\right]\end{array}$ & $\begin{array}{l}85.97 \% @ 0.18 \mathrm{~V} \\
(34 \% @ 0.18 V) \\
(72.5 \% @ 0.45 V)\end{array}$ & $130-\mathrm{nm}$ & $\begin{array}{l}\text { Low } V_{I N} \\
\text { Highest } I_{O U T} \\
\text { High Efficiency } \\
\text { Balances good } \\
\text { PCE and VCE }\end{array}$ & $\begin{array}{l}\text { Off-chip capacitors } \\
\text { Extra complexity for } \\
\text { clocking \& dynamic } \\
\text { bulk-biasing }\end{array}$ \\
\hline Peng et al. (2014) & $\begin{array}{l}\text { Cross-coupled } \\
\text { body- biased \& } \\
\text { backward control } \\
(6 \text {-stages } / 2)\end{array}$ & $320 \mathrm{mV}$ & $450 \mathrm{kHz}$ & $\begin{array}{l}24 \mathrm{pF} \times 12 \\
\text { (on-chip) }\end{array}$ & $C_{L O A D}=50.7 \mathrm{pF}$ & $\begin{array}{l}89 \% @ 0.32 \mathrm{~V} \\
\text { (N/A) }\end{array}$ & $180-\mathrm{nm}$ & $\begin{array}{l}\text { Swift pumping } \\
\text { rate at } 0.1 \mathrm{~ms} \\
\text { Good VCE } \\
\text { Reduce leakages } \\
\text { with body-biasing } \\
\text { for PMOS only }\end{array}$ & $\begin{array}{l}\text { Rather complex scheme } \\
\text { requiring interleaved } \\
\text { inverters and extra } \\
\text { stages at the end }\end{array}$ \\
\hline Zhang and Lee. (2013) & $\begin{array}{l}\text { Dickson based } \\
\text { gain-enhanced } \\
\text { dynamic gate \& } \\
\text { substrate control } \\
(4 \text {-stages/ 1) }\end{array}$ & $900 \mathrm{mV}$ & $7 \mathrm{MHz}$ & $\begin{array}{l}20 \mathrm{pF} \times 4 \\
\text { (on-chip) }\end{array}$ & $\begin{array}{l}C_{L O A D}=40 \mathrm{pF} \\
R_{L O A D}=300 \Omega \\
I_{O U T}=76 \mathrm{uA} \\
@ V_{I N}=1.4 \mathrm{~V} \\
{\left[V_{O U T}=4.5 \mathrm{~V}\right]}\end{array}$ & $\begin{array}{l}84 \% @ 0.90 \mathrm{~V} \\
84.62 \% @ 1.4 \mathrm{~V} \\
(43 \% @ 1.4 V)\end{array}$ & $350-\mathrm{nm}$ & $\begin{array}{l}\text { No } V_{T H} \text { drop } \\
\text { No body-effect } \\
\text { No floating substrate } \\
\text { terminals/ lower } R_{O N}\end{array}$ & $\operatorname{High} V_{I N}$ \\
\hline Chen et al. (2012a) & $\begin{array}{l}\text { Dickson based } \\
\text { dual mode } \\
\text { [startup/ } \\
\text { operation mode] } \\
\text { (10-stages/1) }\end{array}$ & $120 \mathrm{mV}$ & $\begin{array}{l}1 \mathrm{MHz}, \\
\text { (startup) } \\
20 \mathrm{MHz} \\
\text { (operation) }\end{array}$ & $\begin{array}{l}28.6 \mathrm{pF} \times 20 \\
\text { (on-chip) }\end{array}$ & $\begin{array}{l}I_{O U T}=7 \mathrm{uA} \\
@ V_{I N}=0.18 \mathrm{~V} \\
(\text { extrapolation) } \\
{\left[V_{O U T}=0.5 \mathrm{~V}\right]}\end{array}$ & $\begin{array}{l}58.33 \% @ 0.12 \mathrm{~V} \\
(38.8 \% @ 0.12 \mathrm{~V})\end{array}$ & $65-\mathrm{nm}$ & $\begin{array}{l}\text { High PCE } \\
\text { Low } V_{I N} \\
\text { No external } \\
\text { excitation }\end{array}$ & $\begin{array}{l}\text { Low } I_{\text {OUT }} \\
\text { High process cost }\end{array}$ \\
\hline Shih and Otis (2011) & $\begin{array}{l}\text { Bootstrap } \\
\text { (3-stages/ 1) }\end{array}$ & $270 \mathrm{mV}$ & $800 \mathrm{kHz}$ & $\begin{array}{l}25 \mathrm{pF} \times 6 \\
\text { (on-chip) }\end{array}$ & $\begin{array}{l}C_{L O A D}=500 \mathrm{pF} \\
I_{O U T}=5 \mathrm{uA} \\
@ V_{I N}=0.45 \mathrm{~V} \\
{\left[V_{O U T}=0.5 \mathrm{~V}\right]}\end{array}$ & $\begin{array}{l}92.86 \% @ 0.35 \mathrm{~V} \\
(56 \% @ 0.45 V)\end{array}$ & $130-\mathrm{nm}$ & $\begin{array}{l}\text { Fully integrated } \\
\text { Low process cost }\end{array}$ & $\begin{array}{l}\text { Requires } 4 \text { clock } \\
\text { phases } \\
\text { Low } I_{O U T}\end{array}$ \\
\hline Chen et al. (2010) & $\begin{array}{l}\text { Cross-couple } \\
\text { (3-stages/2) }\end{array}$ & $180 \mathrm{mV}$ & $10 \mathrm{MHz}$ & $\begin{array}{l}12.3 \mathrm{pF} \times 6 \\
0.4 \mathrm{pF} \times 2 \\
\text { (on-chip) }\end{array}$ & $\begin{array}{l}C_{L O A D}=12.3 \mathrm{pF} \\
I_{O U T}=8.75 \mathrm{uA} \\
@ V_{I N}=0.18 \mathrm{~V} \\
{\left[V_{O U T}=0.5 \mathrm{~V}\right]}\end{array}$ & $\begin{array}{l}83.33 \% @ 0.18 \mathrm{~V} \\
\text { (N/A) }\end{array}$ & $65-\mathrm{nm}$ & Low $V_{I N}$ & $\begin{array}{l}\text { Low efficiency } \\
\text { Low } I_{\text {OUT }}\end{array}$ \\
\hline Hsieh et al. (2009) & $\begin{array}{l}\text { Static Mixed } \\
\text { Structure } \\
{[\text { CTS + Latched] }} \\
(4-\text {-stage/1) }\end{array}$ & $1.5 \mathrm{~V}$ & $1 \mathrm{MHz}$ & $\begin{array}{l}0.1 \mu \mathrm{F} \times 5 \\
\text { (off-chip) }\end{array}$ & $\begin{array}{l}I_{\text {OUT }}=500 \mu \mathrm{A} \\
V_{I N}=1.5 \mathrm{~V} \\
{\left[V_{\text {OUT }}=7.5 \mathrm{~V}\right]}\end{array}$ & $\begin{array}{l}99.31 \% @ 1.5 \mathrm{~V} \\
(\mathrm{~N} / \mathrm{A})\end{array}$ & $350-\mathrm{nm}$ & High VCE & $\begin{array}{l}\text { Very high } V_{I N} \\
\text { Off-chip } C_{P U M P}\end{array}$ \\
\hline Su and $\mathrm{Ma}(2008)$ & $\begin{array}{l}\text { 4-Phase } \\
\text { Cross-coupled } \\
\text { (2-stages/2) }\end{array}$ & N/A & $4 \mathrm{MHz}$ & $\begin{array}{l}0.5 \mathrm{nF} \times 8 \\
\text { (on-chip) }\end{array}$ & $R_{L O A D}=1.8 \mathrm{k} \Omega$ & $\begin{array}{l}\mathrm{N} / \mathrm{A} \\
(92.01 \%)\end{array}$ & $180-\mathrm{nm}$ & $\begin{array}{l}\text { Good PCE } \\
\text { Low } V_{R} \text { and low } \\
P_{\text {LOss } 1 / 4 \text { sized }} \\
\text { CMOS and } C_{\text {PUMP }} \\
\text { (Reduced reversion } \\
\text { and conduction losses) }\end{array}$ & $\begin{array}{l}\text { Requires } 4 \text { clock } \\
\text { phases }\end{array}$ \\
\hline
\end{tabular}

\section{Discussions and Concluding Remarks}

This review article presents a variety of $\mathrm{CP}$ topologies within the field of LV energy harvesting. These CP topologies are evolving away from discrete, diodeconnected, linear-gain, external start-up structures to the more advanced sub-threshold, cross-coupled, exponentialtype and self start-up structures. Table 2 summarizes these contemporary $\mathrm{CP}$ design trends in the past eight years where gate and substrate control schemes gains substantial attention in low voltage $\mathrm{CP}$ design strategies.

In LV energy harvesting applications, the interaction between harvesters and CPs must be regarded. Low ambient harvesters such as TEGs require CP topologies to compensate for sub- $100 \mathrm{mV}$ range start-up and high pumping efficiency (also VCE). In such situations with sub-threshold voltage and self-start requirements, FBB or DBB of the MOSFET's body-terminal is typically used to reduce threshold voltages for LV applications. These schemes come in expense of higher leakage current on the low $V_{T H}$ conduction path for FBB and circuit complexity or area overhead for DBB. If a more efficient MOSFET turn-on (and better VCE) at low ambient voltages is required, CPs with $V_{T H}$ cancelation or gate voltage augmentation schemes such as bootstrapping CPs and dynamic gate control from augmented voltages of later stages are desired. Otherwise, non-linear type CPs (Exponential CP, Fibonacci (P) may be used for enhanced voltage boosting with reduced stage number.

In designs where low power consumption is desirable, energy recycling with adiabatic type $\mathrm{CP}$ is a solution in expense of slower pumped-up voltages. Alternatively, an adaptive $\mathrm{CP}$ with active/idle mode transition or reconfigurable stages can be considered if extra chip area is available. Good PCE is achievable 
when current drivability of $\mathrm{CP}$ is incremented with lower $R C$ delay and larger MOS devices. The latter has a drawback of higher $V_{T H}$ values, deterring LV start-up. Recent CP designs have typically much higher VCE compared to their PCE. Therefore, balancing between both voltage and power efficiency requires more exploration as it is vital to optimize power transfer between harvester and the $\mathrm{CP}$ circuit while balancing a good pumping efficiency as well. This will be reflected in the proposed hybrid energy harvesting circuit (Lim et al., 2013) where maximum power should be extracted from all three harvesters with impedance matching schemes whereas maximum efficiency should be achieved between the power circuits (e.g., CP or step-up voltage converters) and the load.

For monolithic integration of $\mathrm{CP}$ topologies, $C_{P U M P}$ sizes are kept to $\sim 20-500 \mathrm{pF}$ ranges. Dual branch and latched type CPs with half the pumping capacitor size requirements for the same efficiency of single branches may be a solution.

Some noteworthy achievements at the lower power spectrum $(\mu \mathrm{W})$ have been reported for CPs with PCE up to $\sim 72.5 \%$ at $450 \mathrm{mV}$ supply voltage; recent CP operates with a mere $40 \mathrm{mV}(\mathrm{VCE}=\sim 54 \%)$ input voltage as well as some CPs reaching pumping efficiency up to $\sim 86 \%$ at $180 \mathrm{mV}$ supply voltages.

Challenges to be addressed by future research include developing CP topologies with sub-100 mV start-up voltages and further improving and balancing pumping and power efficiencies at these low ambient voltages. Developing area and power efficient control techniques that optimize harvester usage and CP's charge transferability. Challenges associated to losses and leakages in sub-threshold operation of modern $\mathrm{CP}$ topologies are non-trivial and require more attention in their CP design strategies and leakage management for LV energy harvesting applications.

\section{Conclusion}

This paper recommends the consideration and tradeoffs between the three factors: Voltage, power and form factor when selecting the optimum CP topology to suit a particular low power system especially in micro energy harvesting systems. Hence, future CP designs should consider the three above factors for the possibility of a fully monolithic integration.

\section{Acknowledgement}

The authors acknowledge Micro/Nano-Electronics Systems (MINES) Laboratory, Institute of Microengineering and Nanoelectronics (IMEN), UKM, Malaysia and the Ministry of Higher Education (MOHE), Malaysia for their financial support in this research work.

\section{Author's Contributions}

Michelle Lim Sern Mi: Conducted overview of charge pump topologies, analysis and write-up of the manuscript.

Md. Shabiul Islam: Constructed the research plan, organized and led the research, participated in analysis and contributed to the reviewing of the article critically.

Sawal Hamid Md. Ali and Jahariah Sampe: Involved in the development process of conceptual framework, discussion and development of drafting and review of the article.

\section{Ethics}

The authors have no conflicts of interest in the development and publication of current research.

\section{References}

Ahmed, K.Z. and S. Mukhopadhyay, 2014. A wide conversion ratio, extended input 3.5- $\mu \mathrm{A}$ boost regulator with $82 \%$ efficiency for low-voltage energy harvesting. IEEE Trans. Power Electron., 29: 4776-4786.

DOI: 10.1109/TPEL.2013.2287194

Alioto, M., E. Consoli and J.M. Rabaey, 2013. "EChO" reconfigurable power management unit for energy reduction in sleep-active transitions. IEEE J. SolidState Circuits, 48: 1921-1932.

DOI: $10.1109 /$ JSSC.2013.2258816

Allasasmeh, Y. and S. Gregori, 2009. A performance comparison of Dickson and Fibonacci charge pumps. Proceedings of the European Conference on Circuit Theory and Design, Aug. 23-27, IEEE Xplore Press, Antalya, pp: 599-602. DOI: 10.1109/ECCTD.2009.5275049

Allasasmeh, Y. and S. Gregori, 2011. Switch bootstrapping technique for voltage doublers and double charge pumps. Proceedings of the IEEE International Symposium of Circuits and Systems, May 15-18, IEEE Xplore Press, Rio de Janeiro, pp: 494-497. DOI: 10.1109/ISCAS.2011.5937610

Ansari, M.A., W. Ahmad and S.R. Signell, 2011. Single clock charge pump designed in $0.35 \mu \mathrm{m}$ technology. Proceedings of the 18th International Conference on Mixed Design of Integrated Circuits and Systems, Jun. 16-18, IEEE Xplore Press, Gliwice, pp: 552-556.

Ashraf, M. and N. Masoumi, 2016. A thermal energy harvesting power supply with an internal startup circuit for pacemakers. IEEE Trans. Very Large Scale Integrat., 24: 26-37. DOI: $10.1109 /$ TVLSI.2015.2391442

Atsumi, S., M. Kuriyama, A. Umezawa, H. Banba and K. Naruke et al., 1994. A 16-Mb flash EEPROM with a new self-data-refresh scheme for a sector erase operation. IEEE J. Solid-State Circuits, 77: 791-799. DOI: $10.1109 / 4.280696$ 
Bandyopadhyay, S. and A.P. Chandrakasan, 2012. Platform architecture for solar, thermal and vibration energy combining with MPPT and single inductor. IEEE J. Solid State Circuits, 47: 2199-2215.

DOI: 10.1109/JSSC.2012.2197239

Bandyopadhyay, S., 2013. Energy efficient control for power management circuits operating from nanowatts to watts. PhD. Thesis, Massachusetts Institute of Technology.

Bandyopadhyay, S., P.P. Mercier, A.C. Lysaght, K.M. Stankovic and A.P. Chandrakasan, 2014. A 1.1 nW energy-harvesting system with $544 \mathrm{pW}$ quiescent power for next-generation implants. IEEE J. SolidState Circuits, 49: 2812-2824.

DOI: $10.1109 /$ JSSC.2014.2350260

Bazzini, A., J. Liu and S. Gregori, 2012. A pMOS-based double-ladder integrated charge pump for standard process. Proceedings of the IEEE International Symposium on Circuits and Systems, May 20-23, IEEE Xplore Press, pp: 958-961.

DOI: 10.1109/ISCAS.2012.6272204

Beck, Y. and S. Singer, 2011. Capacitive transposed seriesparallel topology with fine tuning capabilities. IEEE Trans. Circuits Syst. I: Regular Papers, 58: 51-61. DOI: 10.1109/TCSI.2010.2055277

Bender, M.M., M. Cherem Schneider and C. Galup-Montoro, 2014. On the minimum supply voltage for MOSFET oscillators. IEEE Trans. Circuits Syst. I: Regular Papers, 61: 347-357. DOI: $10.1109 /$ TCSI.2013.2278344

Bender, C., 1994. Capacitive ladder networks. IEEE Trans. Circuits Syst. I: Fundamental Theory Applic., 41: 557-558. DOI: 10.1109/81.311548

Carlson, E.J., K. Strunz and B.P. Otis, 2010. A $20 \mathrm{mV}$ input boost converter with efficient digital control for thermoelectric energy harvesting. IEEE J. SolidState Circuits, 45: 741-750. DOI: $10.1109 /$ JSSC.2010.2042251

Cernea, R.A., L. Pham, F. Moogat, S. Chan and B. Le et al., 2009. A $34 \mathrm{MB} / \mathrm{s}$ MLC write throughput $16 \mathrm{~Gb}$ NAND with all bit line architecture on $56 \mathrm{~nm}$ technology. IEEE J. Solid-State Circuits, 44: 186-194. DOI: $10.1109 /$ JSSC.2008.2007152

Chang, L.K. and C.H. Hu, 2004. An exponential-folds design of a charge pump styled DC/DC converter. Proceedings of the IEEE 35th Annual Power Electronics Specialists Conference, Jun. 20-25, IEEE Xplore Press, IEEE Xplore Press, pp: 516-520. DOI: 10.1109/PESC.2004.1355800

Chang, L.K. and C.H. Hu, 2006. High efficiency MOS charge pumps based on exponential-gain structure with pumping gain increase circuits. IEEE Trans. Power Electr., 21: 826-831.

DOI: 10.1109/TPEL.2006.874795
Che, J., C. Zhang, Z. Liu, Z. Wang and Z. Wang, 2009. Ultra-low-voltage low-power charge pump for solar energy harvesting systems. Proceedings of the International Conference on Communications, Circuits and Systems, Jul. 23-25, IEEE Xplore Press, Milpitas, CA, pp: 674-677. DOI: $10.1109 /$ ICCCAS.2009.5250409

Chen, P.H., K. Ishida, K. Ikeuchi, X. Zhang and K. Honda et al., 2011. A 95mV-startup step-up converter with $\mathrm{V}_{\mathrm{TH}}$-tuned oscillator by fixed-charge programming and capacitor pass-on scheme. Proceedings of the IEEE International Solid-State Circuits Conference Digest of Technical Papers, Feb. 20-24, IEEE Xplore Press, San Francisco, CA, pp: 216-218. DOI: 10.1109/ISSCC.2011.5746290

Chen, P.H., K. Ishida, X. Zhang, Y. Okuma and Y. Ryu et al., 2010. 0.18-V input charge pump with forward body biasing in startup circuit using $65 \mathrm{~nm}$ CMOS. Proceedings of the Custom Integrated Circuits Conference, Sept. 19-22, IEEE Xplore Press, San Jose, CA, pp: 1-4. DOI: 10.1109/CICC.2010.5617444

Chen, P.H., X. Zhang, K. Ishida, Y. Okuma and Y. Ryu et al., 2012a. An $80 \mathrm{mV}$ startup dual-mode boost converter by charge-pumped pulse generator and threshold voltage tuned oscillator with hot carrier injection. IEEE J. Solid-State Circuits, 47: 2554-2562. DOI: $10.1109 /$ JSSC.2012.2210953

Chen, P.H., K. Ishida, X. Zhang, Y. Okuma and Y. Ryu et al., 2012b. A 120-mV input, fully integrated dual-mode charge pump in 65-nm CMOS for thermoelectric energy harvester. Proceedings of the 17th Asia and South Pacific Design Automation Conference, Jan. 30-Feb. 2, IEEE Xplore Press, Sydney, NSW, pp: 469-470.

DOI: 10.1109/ASPDAC.2012.6164994

CUI, 2012. CP60 series Peltier Module. CUI Inc.

Dickson, J.F., 1976. On-chip high-voltage generation in MNOS integrated circuits using an improved voltage multiplier technique. IEEE J. Solid-State Circuits, 11: 374-378. DOI: $10.1109 /$ JSSC.1976.1050739

Favrat, P., P. Deval and M.J. Declercq, 1998. A highefficiency CMOS voltage doubler. IEEE J. SolidState Circuits, 33: 410-416. DOI: 10.1109/4.661206

Gariboldi, R. and F. Pulvirenti, 1994. A monolithic quad line driver for industrial applications. IEEE J. SolidState Circuits, 29: 957-962. DOI: 10.1109/4.297702

Gariboldi, R. and F. Pulvirenti, 1996. A $70 \mathrm{~m} \Omega$ intelligent high side switch with full diagnostics. IEEE J. SolidState Circuits, 31: 915-923. DOI: 10.1109/4.508203

Geng, Y. and D. Ma, 2013. Design of reliable $2 \times$ VDD and $3 \times \mathrm{VDD}$ series-parallel charge pumps in nanoscale CMOS. Proceedings of the IEEE International Symposium on Circuits and Systems, May 19-23, IEEE Xplore Press, Beijing, pp: 705-708. DOI: 10.1109/ISCAS.2013.6571944 
Gobbi, L., A. Cabrini and G. Torelli, 2007. A discussion on exponential-gain charge pump. Proceedings of the 18th European Conference on Circuit Theory and Design, IEEE Xplore Press, Seville, pp: 615-618. DOI: 10.1109/ECCTD.2007.4529671

Gupta, A.K., A. Joshi, V. Gajare, H.S. Ghanshyam and A. Dutta, 2013. Power efficient reconfigurable charge pump for micro scale energy harvesting. Proceedings of the IEEE Asia Pacific Conference on Postgraduate Research in Microelectronics and Electronics (PrimeAsia), Dec. 19-21, IEEE Xplore Press, Visakhapatnam, pp: 73-76.

DOI: 10.1109/PrimeAsia.2013.6731181

Hart, D.W., 2011. Power Electronics. 1st Edn., Tata McGraw-Hill, ISBN-10: 0071321209, pp: 477.

Hsieh, Z.H., N.X. Huang, M.S. Shiau, H.C. Wu and D.G. Liu, 2009. An efficiency enhance mixedstructure charge pump. Proceedings of the 12th International Symposium on Integrated Circuits, Dec. 14-16, IEEE Xplore Press, Singapore, pp: 566-569.

Huang, N.X., M.S. Shiau, Z.H. Hsieh, H.C. Wu and D.G. Liu, 2010. Improving the efficiency of mixedstructure charge pumps by the multi-phase technique. Proceedings of the 5th IEEE Conference on Industrial Electronics and Applications, Jun.15-17, IEEE Xplore Press, Taichung, pp: 358-363. DOI: 10.1109/ICIEA.2010.5516888

Im, J.P., S.W. Wang, S.T. Ryu and G.H. Cho, 2012. A 40 $\mathrm{mV}$ transformer-reuse self-startup boost converter with MPPT control for thermoelectric energy harvesting. IEEE J. Solid-State Circuits, 47: 3055-3067. DOI: $10.1109 /$ JSSC.2012.2225734

Kang, S.M., Y. Leblebici and C. Kim, 2014. CMOS Digital Integrated Circuits: Analysis and Design. 1st Edn., McGraw-Hill Higher Education.

Ker, M.D., S.L. Chen and C.S. Tsai, 2006. Design of charge pump circuit with consideration of gateoxide reliability in low-voltage CMOS processes. IEEE J. Solid-State Circuits, 41: 1100-1107. DOI: $10.1109 /$ JSSC.2006.872704

Keung, K.M., V. Manne and A. Tyagi, 2007. A novel charge recycling design scheme based on adiabatic charge pump. IEEE Trans. Very Large Scale Integrat. Syst., 15: 733-745. DOI: 10.1109/TVLSI.2007.899220

Kim, J. and C. Kim, 2013. A DC-DC boost converter with variation-tolerant MPPT technique and efficient ZCS circuit for thermoelectric energy harvesting applications. IEEE Trans. Power Electron., 28: 3827-3833.

DOI: 10.1109/TPEL.2012.2231098

Kim, J., P.K. Mok and C. Kim, 2015. A 0.15 V input energy harvesting charge pump with dynamic body biasing and adaptive dead-time for efficiency improvement. IEEE J. Solid-State Circuits, 50: 414-425. DOI: 10.1109/JSSC.2014.2375824

Kleveland, B., 2002. Multi-stage charge pump. U.S. Patent 6,486,728. Matrix Semiconductor, Inc.
Lauterbach, C., W. Weber and D. Römer, 2000. Charge sharing concept and new clocking scheme for power efficiency and electromagnetic emission improvement of boosted charge pumps. IEEE J. Solid-State Circuits, 35: 719-723. DOI: $10.1109 / 4.841499$

Lee, K.H., Y.J. Woo, H.S. Han, K.C. Lee and C.S. Chae et al., 2008. Power-efficient series-charge parallel-discharge charge pump circuit for LED drive. Proceedings of the Power Electronics Specialists Conference, Jun. 15-19, IEEE Xplore Press, Rhodes, pp: 2645-2649. DOI: 10.1109/PESC.2008.4592341

Lim, M.S.M., S.H.M. Ali and M.S. Islam, 2013. A novel architecture of maximum power point tracking for ultra-low-power based hybrid energy harvester in ubiquitous devices: A review. Am. J. App. Sci., 10: 1240-1251.

DOI: 10.3844/ajassp.2013.1240.1251

Lim, M.S.M., S.H.M. Ali, S. Jahariah and M.S. Islam, 2014. Modelling of hybrid energy harvester with DC-DC boost converter using arbitary input sources for ultra-low-power micro-devices. Proceedings of the IEEE International Conference on Semiconductor Electronics, Aug. 27-29, IEEE Xplore Press, Kuala Lumpur, pp: 28-31. DOI: 10.1109/SMELEC.2014.6920787

Liu, Q., X. Wu, M. Zhao, L. Wang and X. Shen, 2012. 30-300 mV input, ultra-low power, self-startup DC-DC boost converter for energy harvesting system. Proceedings of the IEEE Asia Pacific Conference on Circuits and Systems, Dec. 2-5, IEEE Xplore Press, Kaohsiung, pp: 432-435. DOI: 10.1109/APCCAS.2012.6419064

Lu, C., S.P. Park, V. Raghunathan and K. Roy, 2010. Efficient power conversion for ultra low voltage micro scale energy transducers. Proceedings of the Conference on Design, Automation and Test in Europe, Mar. 8-12, IEEE Xplore Press, Dresden, pp: 1602-1607. DOI: 10.1109/DATE.2010.5457066

Luo, F.L. and H. Ye, 2010. Power Electronics: Advanced Conversion Technologies. 1st Edn., CRC Press, ISBN-10: 1439882614, pp: 744.

Luo, F.L. and H. Ye, 2009. Investigation of switchedcapacitorized DC/DC converters. Proceedings of the IEEE 6th International Power Electronics and Motion Control Conference, May 17-20, IEEE Xplore Press, Wuhan, pp: 1270-1276. DOI: 10.1109/IPEMC.2009.5157581

Luo, F.L., 2009. Switched-capacitorized DC/DC converters. Proceedings of the 4th IEEE Conference on Industrial Electronics and Applications, May 25-27, IEEE Xplore Press, Xi'an, pp: 1074-1079.

DOI: 10.1109/ICIEA.2009.5138366

Makowski, M.S. and D. Maksimovic, 1995. Performance limits of switched-capacitor DC-DC converters. Proceedings of the 26th Annual IEEE Power Electronics Specialists Conference, Jun. 18-22, IEEE Xplore Press, Atlanta, GA, pp: 1215-1221. DOI: 10.1109/PESC.1995.474969 
Maksimovic, D. and S. Dhar, 1999. Switched-capacitor DC-DC converters for low-power on-chip applications. Proceedings of the 30th Annual IEEE Power Electronics Specialists Conference, Jul. 1-1, IEEE Xplore Press, Charleston, SC, pp: 54-59. DOI: 10.1109/PESC.1999.788980

Meindl, J.D. and J.A. Davis, 2000. The fundamental limit on binary switching energy for Terascale Integration (TSI). IEEE J. Solid-State Circuits, 35: 1515-1516. DOI: $10.1109 / 4.871332$

MIDE, 2013. Piezoelectric energy harvesters. MIDE.

Mondal, S. and R.P. Paily, 2013. A strategy to enhance the output voltage of a charge pump circuit suitable for energy harvesting. Proceedings of the International Conference on Microelectronics, Communications and Renewable Energy, Jun. 4-6, IEEE Xplore Press, Kanjirapally, pp: 1-5. DOI: 10.1109/AICERA-ICMiCR.2013.6575933

Nakagome, Y., H. Tanaka, K. Takeuchi, E. Kume and Y. Watanabe et al., 1991. An Experimental 1.5-V 64Mb DRAM. IEEE J. Solid-State Circuits, 26: 465-472. DOI: $10.1109 / 4.75040$

New, L.F., Z.A.B.A. Aziz and M.F. Leong, 2012. A low ripple CMOS charge Pump for low-voltage application. Proceedings of the 4th International Conference on Intelligent and Advanced Systems, Jun. 12-14, IEEE Xplore Press, Kuala Lumpur, pp: 784-789. DOI: 10.1109/ICIAS.2012.6306120

Palumbo, G. and D. Pappalardo, 2010. Charge pump circuits: An overview on design strategies and topologies. IEEE Circuits Syst. Magazine, 10: 31-45. DOI: 10.1109/MCAS.2009.935695

Pan, F. and T. Samaddar, 2010. Charge Pump Circuit Design. 1st Edn., McGraw Hill Professional, New York, ISBN-10: 0071491422, pp: 247.

Pelliconi, R., D. Iezzi, A. Baroni, M. Pasotti and P.L. Rolandi, 2003. Power efficient charge pump in deep submicron standard CMOS technology. IEEE J. Solid-State Circuits, 38: 1068-1071.

DOI: $10.1109 /$ JSSC.2003.811991

Peng, H., N. Tang, Y. Yang and D. Heo, 2014. CMOS startup charge pump with body bias and backward control for energy harvesting step-up converters. IEEE Trans. Circuits Syst. I: Regular Papers, 61: 1618-1628. DOI: 10.1109/TCSI.2013.2290823

Perez-Nicoli, P., P.C. Lisboa, F. Veirano and F. Silveira, 2015. A series-parallel switched capacitor step-up DCDC converter and its gate-control circuits for over the supply rail switches. Analog Integrated Circuits Signal Process., 85: 37-45. DOI: 10.1007/s10470-015-0573-4

Ramadass, Y.K. and A.P. Chandrakasan, 2010. A batteryless thermoelectric energy-harvesting interface circuit with $35 \mathrm{mV}$ startup voltage. Proceedings of the IEEE International Solid-State Circuits Conference, Feb. 7-11, IEEE Xplore Press, San Francisco, CA, pp: 486-487. DOI: 10.1109/ISSCC.2010.5433835
Roy, K., V. Raghunathan, C. Lu and S.P. Park, 2014. Efficient power conversion for ultra low voltage micro scale energy transducers. Purdue Research Foundation.

SANYO, 2008. Amorphous solar cell datasheet: Amorton AM-1417. SANYO.

Seeman, M.D. and S.R. Sanders, 2008. Analysis and optimization of switched-capacitor DC-DC converters. IEEE Trans. Power Electron., 23: 841-851.

DOI: 10.1109/TPEL.2007.915182

Shao, H., C.Y. Tsui and W.H. Ki, 2006. A charge based computation system and control strategy for energy harvesting applications. Proceedings of the IEEE International Symposium on Circuits and Systems, May 21-24, IEEE Xplore Press, Island of Kos, pp: 1-4. DOI: $10.1109 /$ ISCAS.2006.1693239

Shi, C., B. Miller, K. Mayaram and T. Fiez, 2011. A multiple-input boost converter for low-power energy harvesting. IEEE Trans. Circuits Syst. II: Express Briefs, 58: 827-831.

DOI: 10.1109/TCSII.2011.2173974

Shih, Y.C. and B.P. Otis, 2011. An inductorless DC-DC converter for energy harvesting with a $1.2-\mu \mathrm{W}$ bandgap-referenced output controller. IEEE Trans. Circuits Syst. II: Express Briefs, 58: 832-836. DOI: 10.1109/TCSII.2011.2173967

Su, F., W.H. Ki and C.Y. Tsui, 2005. Gate control strategies for high efficiency charge pumps. Proceedings of the IEEE International Symposium on Circuits and Systems, May 23-26, IEEE Xplore Press, pp: 1907-1910.

DOI: $10.1109 /$ ISCAS.2005.1464985

$\mathrm{Su}, \mathrm{L}$. and D. Ma, 2008. Design and optimization of integrated low-voltage low-power monolithic CMOS charge pumps. Proceedings of the International Symposium on Power Electronics, Electrical Drives, Automation and Motion, Jun. 11-13, IEEE Xplore Press, Ischia, pp: 43-48. DOI: 10.1109/SPEEDHAM.2008.4581247

Sun, Y.M. and X.B. Wu, 2010. Subthreshold voltage startup module for stepup DC-DC converter. Electron. Lett., 46: 373-373. DOI: 10.1049/el.2010.3448

Tan, Y.K., 2013. Energy Harvesting Autonomous Sensor Systems: Design, Analysis and Practical Implementation. 1st Edn., CRC Press, ISBN-10: 1439892733, pp: 254.

Tanzawa, T., T. Tanaka, K. Takeuchi and H. Nakamura, 2002. Circuit techniques for a 1.8-V-only NAND flash memory. IEEE J. Solid-State Circuits, 37: 84-89. DOI: $10.1109 / 4.974549$

Teh, Y.K. and P.K. Mok, 2014. Design of transformerbased boost converter for high internal resistance energy harvesting sources with $21 \mathrm{mV}$ self-startup voltage and $74 \%$ power efficiency. IEEE J. Solid-State Circuits, 49: 2694-2704.

DOI: $10.1109 / J S S C .2014 .2354645$ 
Ueno, F., T. Inoue, I. Oota and I. Harada, 1991. Emergency power supply for small computer systems. Proceedings of the IEEE International Sympoisum on Circuits and Systems, Jun. 11-14, IEEE Xplore Press, pp: 1065-1068.

DOI: $10.1109 /$ ISCAS.1991.176549

Ulaganathan, C., B.J. Blalock, J. Holleman and C.L. Britton Jr, 2012. An ultra-low voltage self-startup charge pump for energy harvesting applications. Proceedings of the IEEE 55th International Midwest Symposium on Circuits and Systems, Aug. 5-8, IEEE Xplore Press, Boise, ID, pp: 206-209. DOI: 10.1109/MWSCAS.2012.6291993

Umezawa, A., S. Atsumi, M. Kuriyama, H. Banba and K.I. Imamiya et al., 1992. A 5-V-only operation 0.6$\mu \mathrm{m}$ flash EEPROM with row decoder scheme in triple-well structure. IEEE J. Solid-State Circuits, 27: 1540-1546. DOI: 10.1109/4.165334

Vaisband, I., M. Saadat and B. Murmann, 2015. A closedloop reconfigurable switched-capacitor dc-dc converter for sub-mW energy harvesting applications. IEEE Trans. Circuits Syst. I: Regular Papers, 62: 385-394. DOI: 10.1109/TCSI.2014.2362971

Weng, P.S., H.Y. Tang, P.C. Ku, and L.H. Lu, 2013. 50 $\mathrm{mV}$-input batteryless boost converter for thermal energy harvesting. IEEE J. Solid-State Circuits, 48: 1031-1041. DOI: 10.1109/JSSC.2013.2237998

Wu, J.T. and K.L. Chang, 1998. MOS charge pumps for low-voltage operation. IEEE J. Solid-State Circuits, 33: 592-597. DOI: 10.1109/4.663564
Yeo, K.H., M.S. Islam, S. Menon, S.A. Wahab and S.H.M. Ali, 2015. Comparison of CMOS rectifiers for micropower energy harvesters. Proceedings of the IEEE International Conference on Energy Conversion, Oct. 19-20, IEEE Xplore Press, Johor Bahru, pp: 419-423. DOI: 10.1109/CENCON.2015.7409581

Yeo, K.H., M.S. Islam. S. Menon, S.A. Wahab and S.H.M. Ali, 2016. Architecture of an ultra-low-power fully autonomous universal power conditioner of energy harvester for wireless sensor networks: A review. Am. J. Applied Sci., 1: 326.334. DOI: 10.3844/ajassp.2016.326.334

Zhang, H., M. Zhao, S. Liu, Y. Fang and X. Wu, 2014. A 20-300mV transformer-based self-startup flyback converter with MPPT and ZCS control for thermoelectric energy harvesting. Proceedings of the IEEE 57th International Midwest Symposium on Circuits and Systems, Aug. 3-6, IEEE Xplore Press, College Station, TX, pp: 41-44. DOI: 10.1109/MWSCAS.2014.6908347

Zhang, X. and H. Lee, 2010. An Efficiency-Enhanced Auto-Reconfigurable $2 \times / 3 \times$ SC Charge Pump for Transcutaneous Power Transmission. IEEE J. Solid-State Circuits, 45: 1906-1922. DOI: $10.1109 /$ JSSC.2010.2055370

Zhang, X. and H. Lee, 2013. Gain-enhanced monolithic charge pump with simultaneous dynamic gate and substrate control. IEEE Trans. Very Large Scale Integrat. Syst., 21: 593-596. DOI: 10.1109/TVLSI.2012.2190149 